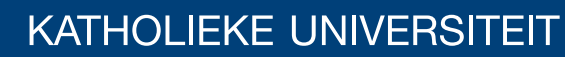 \\ LEUVEN
}

\section{Faculty of Business and Economics}

The Asymmetric Effects of Scarcity and Abundance on Storable Commodity Price Dynamics and Hedge Ratios

Katelijne A.E. Carbonez, Van T.T. Nguyen, Piet Sercu

DEPARTMENT OF ACCOUNTANCY, FINANCE AND INSURANCE (AFI) 


\title{
The Asymmetric Effects of Scarcity and Abundance on Storable Commodity Price Dynamics and Hedge Ratios*
}

\author{
Katelijne A.E. Carbonez ${ }^{\dagger}$ \\ Van T.T. Nguyen ${ }^{\ddagger}$ \\ Piet $\mathrm{Sercu}^{\S}$
}

Tuesday $23^{\text {rd }}$ February, 2010

\begin{abstract}
This paper revisits the asymmetric effect of the basis on commodity spot and futures price volatilities documented by Kogan, Livdan and Yaron (2008) and Lien and Yang (2008). Kogan et al. (2008) show both theoretically and empirically that, for a nonstorable consumption good, the relationship between commodity price volatility and the basis exhibits a V-shape. Lien and Yang (2008) illustrate the existence of an asymmetric effect of the basis on commodity price volatilities for storable commodities. Their results seem to imply that both scarcity and abundance increase spot and futures price volatility, a counter-intuitive result. The aim of this article is twofold: (i) test the presence and the robustness of the asymmetric effect for storable agricultural commodities by analyzing different sample periods, longer horizons and alternative utility functions; and - given that this asymmetric effect turns out not to be robust - (ii) explore new variables besides the basis to proxy for scarcity, analyze whether they exhibit an asymmetric effect and test their performance in modeling storable commodity price volatility and in hedging futures positions.

Our results provide little support for a V-shaped relationship between the basis and storable agricultural commodity price volatilities. Though an asymmetric effect is present in that the size of the coefficient for a positive basis is much larger than for a negative
\end{abstract}

\footnotetext{
*We gratefully acknowledge financial support from FWO and ICM, and help with the data from the USDA and Scott Irwin. We also thank Philip Garcia, Charles Nelson and the participants of the Advanced Research and Scholarly Communications Course of the University of Illinois at Urbana-Champaign for useful comments. All errors are the authors'.

${ }^{\dagger}$ ICM PhD Fellow at Leuven School of Business and Economics, K.U.Leuven, Naamsestraat 69, B-3000 Leuven; +32 163266 59; Katelijne.Carbonez@econ.kuleuven.be

${ }^{\ddagger}$ FWO PhD Fellow at Leuven School of Business and Economics, K.U.Leuven, Naamsestraat 69, B-3000 Leuven; +32 163264 62; thituongvan.nguyen@econ.kuleuven.be

${ }^{\S}$ Leuven School of Business and Economics, K.U.Leuven, Naamsestraat 69, B-3000 Leuven; +32 163267 56; Piet.Sercu@econ.kuleuven.be
} 
basis, a negative basis does not lead to higher volatilities. Moreover, we find that the strong hedging performance documented by Lien and Yang (2008) when including the asymmetric basis in the volatility specification is not robust across sample periods, for longer hedging horizons and for alternative utility functions. More positively, though, our results indicate that alternative scarcity specifications do have the expected positive link with volatility and often outperform more simple models in terms of hedging performance. Unfortunately, no single variable consistently leads to better results out-of-sample and there is often no correspondence between the best performing model in- and out-of-sample.

\section{Introduction}

The theory of storage developed by Kaldor (1939), Working (1948, 1949), Brennan (1958) and Telser (1958) explains the typical intertemporal price behavior to be found in storable commodity markets by linking storage decisions to spot and futures price movements. An unexpected shortfall in harvest due to bad weather for example not only influences the futures price for delivery after the harvest but also the spot price because inventory holders will adjust their stocks to maximize income. The high price expected in the future induces inventory holders to hold on to their stocks and leads to a related increase in the current spot price.

Fama and French (1987) and Ng and Pirrong (1994) extend the theory of storage and show how fundamentals influence spot and futures prices volatility and correlation as well as spot and futures price returns. In their discussion, fundamental demand- and supply conditions are proxied for by the basis and the convenience yield. More specifically, they argue that the volatility of the spot and futures prices increases and the correlation between spot and futures prices decreases as inventories are depleted. Moreover, they explain how spot price volatility increases more than futures price volatility. Their argument starts from the proposition that supply conditions become more constrained as inventories decrease. The resulting drop in the elasticity of supply leads to an increase in the variability of spot and futures prices. Spot price volatility increases more than futures price volatility because agents can adjust real variables more easily in the long run than in the short run, i.e. short-run elasticity is lower then long-run elasticity. Finally they discuss how the correlation between spot and futures prices decreases because the probability of a stock-out increases when inventories become scarce. A stock-out leads to a temporary disconnect between the spot and futures prices as arbitrage activities are impaired. As a result, Ng and Pirrong (1994) conclude that hedge ratios, the ratio of the covariance between spot and futures prices and the variance of futures prices, decline with 
scarcity.

According to recent research by Kogan, Livdan and Yaron (2008) the relationship between commodity price volatility and the slope of the term structure of prices (i.e. the basis) exhibits a V-shape. They derive an equilibrium model in a production economy with investment constraints and show empirically that the relationship holds for daily oil futures volatilities. However, their model is built based on the assumption of a non-storable consumption good, and is as such not applicable to agricultural commodities (or even oil, for that matter). Lien and Yang (2008) nevertheless find that the asymmetric effect of the basis on daily commodity price volatility is also present for a wide range of storable commodities. The evidence of Kogan et al. (2008) and Lien and Yang (2008) suggests that both scarcity (a negative basis) and abundance (a positive basis) increase daily commodity spot and futures price volatilities, albeit in an asymmetric way - a counter-intuitive result. Logically, in periods of abundance supply-and-demand shocks can be easily absorbed by the system and price effects should be minimal.

The link between scarcity/abundance and the variance-covariance structure of spot and futures prices documented in the literature suggests that a measure of scarcity/abundance should be incorporated in any model of the variance-covariance of spot and futures prices. It then also suggests that dynamic hedge ratios should take this relationship into account as was done by Ng and Pirrong (1994) and Lien and Yang (2008).

This study presents and discusses new dynamic hedge ratios incorporating scarcity/ abundance using a bivariate GARCH model for storable agricultural commodities such as corn, wheat and soybeans. First, this paper re-examines the asymmetric effect of scarcity and abundance on commodity price volatilities for storable agricultural commodities such as corn, wheat and soybeans and tests its implications for hedging. More specifically, we test the presence and the robustness of the asymmetric effect by analyzing different sample periods, longer horizons and alternative utility functions. Unfortunately, we do not find consistent evidence in favor of the asymmetric effect, at least when we use the basis as a proxy for scarcity as Lien and Yang (2008).

Second, this paper contributes to the literature by exploring whether other variables besides the basis are a better proxy for scarcity, analyzes the presence of an asymmetric effect and compares their performance in modeling storable commodity price volatility and in hedg- 
ing futures positions with scarcity measures commonly used in the literature. Typically, the existing literature uses the basis (the difference between the spot and the futures price) or the convenience yield (the basis adjusted for storage costs and interest rates) as a proxy for scarcity. This focus on the basis and the convenience yield is directly related to the theory of storage developed by Kaldor (1939), Working (1948, 1949), Brennan (1958) and Brennan (1991). Inventory holders in commodity markets are rewarded for holding inventory through a return on storage. This return on storage consists of the storage cost, the opportunity cost minus the convenience yield, a stream of implicit benefits that accrue to the holders of the commodity. These benefits arise from increased flexibility in reacting to unexpected supply-and-demand shocks and from avoiding production disruptions when inventories are scarce. Working (1933) and Brennan (1958) were pioneers in showing that the convenience yield is a decreasing nonlinear function of inventory levels. The convenience yield is high when the commodity is scarce and goes to zero when inventories are abundant. As such the convenience yield serves as a proxy for scarcity. Using the convenience yield and a bivariate GARCH model, Ng and Pirrong (1994) show that the hedge ratio for metals can change dramatically when scarcity is included in the model. However, they do not test the performance of these hedge ratios compared to the more traditional hedge ratios used in the literature such as the one-to-one hedge, the minimum variance hedge as computed by OLS, and the dynamic minimum variance hedge computed by a standard bivariate GARCH. Lien and Yang (2008) include an asymmetric basis effect in the variance-covariance structure of spot and futures prices using a bivariate GARCH model and find that their resulting dynamic hedge ratios outperform the more traditional hedge ratios for a wide range of commodities.

The existing literature never questions the basis and the convenience yield as a proxy for scarcity. While other proxies might produce more effective results, a strong case can be made for using the basis. First, the measure is readily available and not subject to data errors. Second, the basis has been shown in the past to correlate with inventory levels in a similar way as the convenience yield. And third, it also includes a convergence effect that influences the variance and covariance of spot and futures returns. Since Working, the convenience yield is also an obvious choice as a measure for scarcity. First, the convenience has been shown to be a nonlinear function of inventories. The lower the level of inventories, the higher the convenience yield. Second, the convenience yield corrects the basis for storage costs and opportunity costs and as such should be a more accurate measure than the basis to reflect scarcity. Unfortunately, 
the convenience yield is an unobservable variable and has to be derived from other variables. Therefore, it may be noisy due to data errors.

We propose additional measures for scarcity/abundance. One measure we investigate is the deviation of actual inventory level from its long-term trend. We have data on weekly inventory data for corn, wheat and soybeans between 1989 and 2008, and between 1885 and 1935, for warehouses regular for delivery in Chicago and Toledo. We also have quarterly data of the state-by-state on- and off-farm inventories. Next to the inventory measures, we also study the spot price as a proxy for scarcity. More specifically, we look at the deviation of the spot price from its short-term trend. Brennan (1991) and others have proposed the spot price as a sufficient statistic, in the sense that the spot price should reflect demand and supply conditions. Price data are also convenient because - like the basis - they avoid measurement issues present in some of the other variables. Deviations of the spot price from its short-term trend are likely to be a reflection of both short-term demand fluctuations and one-off supply shocks at harvest. Last, we consider all measures combined as a proxy for scarcity and abundance. Each scarcity measure may add additional information in the model and thus lead to the best proxy for scarcity.

Third, the article contributes to the literature by analyzing different sample periods, studies longer hedging horizons and tests hedging performance for agents with alternative utility functions. In research, prior results are always limited by the sample period that was analyzed. Often, optimal hedge ratios in one sample period break down in another sample. While Lien and Yang (2008) study a long sample, 1980 to 1999, and also find consistent results on subsamples, 1980-1989 vs 1990-1999, we wonder whether the strong improvement in utility the authors document depends on their chosen sample period. Indeed, the sample period covers a relatively stable period for commodity markets. Except for 1996, at least for agricultural commodity markets, prices were quite stable and markets relatively predictable. Additionally, the only volatile year in their sample - 1996 - is nicely buffered by more calm periods in the tests and sub-samples so that its impact is possibly diluted. Finally, the first period they consider is characterized by government stockholding schemes. Leaving out the eighties but including the more recent period of highly volatile prices and convergence breakdown might affect the results significantly. In periods where the convergence between spot and futures prices breaks down, arbitrage is obviously impaired. What then is the meaning of the basis in such periods, 
and can it still reflect scarcity? If the basis is not an accurate measure, including it in the variance-covariance structure could lead to biased results. To ensure our results are not limited by the sample period, we test a very extensive dataset spanning the period 1885 to 1935 , and 1989 to 2008.

The prior literature on hedging when taking into account the (asymmetric) basis has focused on a daily hedging horizon. However, daily hedges are not really used in practice, and daily rebalancing for longer horizon hedging also seems unlikely. ${ }^{1}$ In their review of the futures hedge ratio literature, Chen, Lee and Shrestha (2003) note that, ideally, the hedge horizon should match the data frequency. With our dataset, we can easily test a weekly and a monthly hedging horizon. A quarterly horizon is not feasible due to insufficient data. Overlapping regressions would be a solution to insufficient data, but they in turn would lead to other econometric issues that we prefer to avoid in this study.

The results are threefold.

First, we find that the strong improvement in hedging performance documented by Lien and Yang (2008) when including the asymmetric basis in the volatility specification is not robust across commodities, sample periods, for longer hedging horizons and for alternative utility functions. Consistently with the findings of Ng and Pirrong (1994), the significant results of Lien and Yang (2008) seem to be driven by the fact that fundamentals have a short-term effect on volatility. Given that the basis picks up short-term phenomena, including the basis as an additional variable in the GARCH specification adds very little in applications on weekly or monthly frequencies. The fact that the strong performance of the Lien and Yang (2008) paper is not robust across commodities and sample periods, is more serious and seriously invalidates the model.

Second, the bivariate GARCH estimation results for the contemporary and the pre-WWII data indicate that most measures under study have a significant effect on spot and futures price volatility, certainly at the daily and weekly frequency. Moreover, the coefficients are consistent with the presence of limited asymmetries but they provide little support for a V-shaped rela-

\footnotetext{
${ }^{1}$ An feasible alternative to daily re-balancing, is a daily update of the hedging strategy that is only implemented if the expected utility of re-balancing exceeds the expected utility of doing nothing. This clearly reduces the number of transactions (see Lien and Yang (2008) and Carbonez, Nguyen and Sercu (2008) for an illustration of this technique).
} 
tionship between the scarcity/abundance variables and storable agricultural commodity price volatilities.

Third, in line with the above, the results show that the alternative scarcity variables increase volatility while the abundance variables decrease volatility. Including this effect in the hedge ratio specification often leads to a superior hedging performance. Moreover, using the best model leads to significant reductions in out-of-sample portfolio variance, indicating that investors have a substantial benefit in looking for the appropriate model. Unfortunately, based on the results, it seems very hard to find the best out-of-sample model as the best model is not consistent across commodities and sample periods and as there is no correspondence between the best in-sample and the best out-of-sample model.

\section{Methodology}

\subsection{The dynamics of spot and futures returns and their volatilities}

The theory of storage (Working, 1948, 1949, and Telser, 1958) predicts that spot and futures prices respond similarly to shocks in the long run. Empirical research on the adjustment of spot and futures prices to information confirms these theoretical predictions. As a result, spot and futures prices are typically cointegrated. More specifically, Kroner and Sultan (1993), Ng and Pirrong (1994), Yang et al. (2001), and Lien and Yang $(2006,2008)$ have shown that spot and futures prices can be described by a cointegrated system with the basis entering into the error correction term. More specifically, the conditional mean equations of spot and futures returns are well approximated by the following linear projections:

$$
\begin{aligned}
& r_{s, t}=\alpha_{s}+\Sigma_{n=1}^{p} \beta_{s, n} r_{s, t-n}+\Sigma_{n=1}^{q} \beta_{f, n} r_{f, t-n}+\gamma_{s} B_{t-1}+\varepsilon_{s, t}, \\
& r_{f, t}=\alpha_{f}+\Sigma_{n=1}^{p} \beta_{s, n} r_{s, t-n}+\Sigma_{n=1}^{q} \beta_{f, n} r_{f, t-n}+\gamma_{f} B_{t-1}+\varepsilon_{f, t}
\end{aligned}
$$

where $r_{s, t}=100 * \frac{S_{t}-S_{t-1}}{S_{t-1}}$ and $r_{f, t}=100 * \frac{F_{t}-F_{t-1}}{F_{t-1}}$ are the spot and futures simple returns respectively, $p$ and $q$ are the number of lags, and $B_{t-1}=S_{t-1}-F_{t-1}$ is the lagged basis. Given the expected comovement of spot and futures prices in the long run, spot prices must tend to fall and futures prices must tend to increase when the basis is positive and vice versa. Hence, 
we expect $\gamma_{s} \leq 0$ and $\gamma_{f} \geq 0$ and $\gamma_{f}-\gamma_{s}>0 .^{2}$

To account for the fact that the variance-covariance of spot and futures returns is timevarying, we adopt a bivariate GARCH specification to model the variance-covariance matrix. More specifically, the symmetric conditional variance-covariance matrix of the residuals from the mean equation Eq. (1) is given by

$$
\operatorname{Var}\left(\varepsilon_{s, t}, \varepsilon_{f, t} \mid I_{t}\right) \equiv V_{t}=\left(\begin{array}{cc}
\sigma_{s, t}^{2} & \sigma_{s f, t} \\
\sigma_{s f, t} & \sigma_{f, t}^{2}
\end{array}\right),
$$

given $I_{t}$, the information set at $t$. The time-varying conditional variances of spot and futures returns are modeled as a constant conditional correlation bivariate GARCH model using the following specification: ${ }^{3}$

$$
\begin{aligned}
\sigma_{s, t}^{2} & =\delta_{s}+\theta_{s} \varepsilon_{s, t-1}^{2}+\lambda_{s} \sigma_{s, t-1}^{2}+\Phi_{j, s} \Xi_{j, t-1}+\eta_{s, t}, \\
\sigma_{f, t}^{2} & =\delta_{f}+\theta_{f} \varepsilon_{f, t-1}^{2}+\lambda_{f} \sigma_{f, t-1}^{2}+\Phi_{j, f} \Xi_{j, t-1}+\eta_{f, t}, \\
\sigma_{s f, t} & =\rho_{s f} \sqrt{\sigma_{s, t} \sigma_{f, t}}
\end{aligned}
$$

where $\sigma_{s, t}^{2}$ and $\sigma_{f, t}^{2}$ denote the time-varying conditional variance of spot and futures returns, $\sigma_{s f, t}$ the time-varying conditional covariance of spot and futures returns, $\Phi_{j}$ a vector of coefficients assigned to $\Xi_{j}$ a number of exogenous variables representing scarcity and/or abundance that are assumed to influence the variances of spot and futures returns. For each model $j$ of scarcity/abundance, we test the following specifications for the vector $\Xi_{j}:$ (i) $\Xi_{j}=\left[\xi_{j}^{+}, \xi_{j}^{-}\right]$, (ii) $\Xi_{j}=\left[\xi_{j}^{+}\right]$, (iii) $\Xi_{j}=\left[\xi_{j}^{-}\right]$, or (iv) $\Xi_{j}=\left[\xi_{j}\right]$. When we take the example of the basis model, $\xi_{j}^{+}$ is equal to $\max (B, 0), \xi_{j}^{-}$is $\min (B, 0)$ and $\xi_{j}$ is $B$, where $B$ is the basis, specified as the spot minus the futures price. For each sample period and each model analyzed, we then choose the best in-sample model as the base model for the out-of-sample comparison, using the standard information criteria.

\footnotetext{
${ }^{2}$ Spot and futures prices should respond similarly in the presence of sufficient inventory but in periods of scarcity spot and futures price behavior can differ as discussed in the introduction. However, the empirical results still indicate a cointegrated relationship for all periods as discussed in the results section.

${ }^{3}$ Please note that our specification differs from the Lien and Yang (2008) specification. They use a dynamic conditional correlation GARCH model as proposed by Engle (2002) and Tse and Tsui (2002).
} 


\subsection{Measures of scarcity and abundance}

In the literature, scarcity and abundance are typically proxied for by either the basis, i.e. the spot price minus the futures price, or the convenience yield, i.e. the basis adjusted for storage costs and interest charges. We propose new measures for scarcity and abundance, and test whether they have an asymmetric effect on the variance-covariance of spot and futures prices. We also test their performance when they are included to compute hedge ratios.

\subsubsection{Actual inventory levels}

Inventory levels are an obvious measure scarcity or abundance. For our application, we use two measures of inventory: (i) actual weekly inventory levels at warehouses regular for delivery of CBOT contracts and (ii) actual quarterly on-farm and off-farm inventory levels in Illinois and Ohio as given by the USDA quarterly survey of stocks. The former measure has the advantage of being a high-frequency inventory level. However, it does not reflect the right economic idea. Scarcity or abundance is not defined by inventories that are available at warehouses regular for delivery only, but also by stocks that are available for delivery in the region and can easily be shipped to the warehouses regular for delivery. Hence we also use the latter low-frequency measure, a more accurate reflection of grain availabilities in the states where delivery is possible.

To reflect any asymmetric effect of inventory levels, we take the percentage deviations of inventory levels from their long-term trend. This trend in inventory levels is meant to reflect long-term trends in production capacity and consumption levels. As a result, correcting actual inventory levels by their long-term trend should be a more accurate reflection of scarcity and abundance than actual inventories. For the quarterly data, we start by deseasonalizing inventory levels and compute the long-term trend on the deseasonalized data. ${ }^{4}$

\footnotetext{
${ }^{4}$ The long-term trend is computed as the Hodrick-Prescott trend. On the basis of eyeball tests we settled for a smoothness parameter of 1.05 billion for the weekly data and a smoothness parameter of 1600 for the quarterly data. To interpret this, one can refer to the standard values for the smoothness parameter $\lambda_{q}$ in quarterly series: 1,600 for quarterly series with peak-to-peak cycles of short duration (roughly 10 year), and 160,000 for cycles of about 30 years or longer. Gorton et al. (2007), for instance, use 160,000. To translate $\lambda_{q}$ into an equivalent for weekly data, Ravn and Uhlig (2002) recommend multiplication by the fourth power of the relative frequency. Taking 4 weeks in a month, we would get $\lambda_{w}=\lambda_{q} \times 12^{4}=50000 \times 20736$, implying an equivalent quarterly smoothness of $\lambda_{q}=50,000$, nicely in-between the 1600 and 160,000 standards.
} 
Figure 1: Seasonality patterns of inventory levels for wheat, corn and soybeans - period 1986-2008

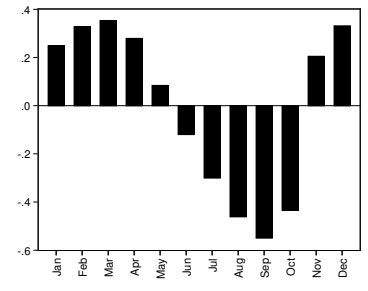

(a) Corn

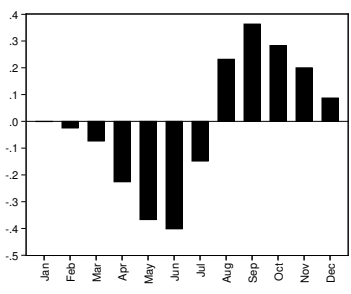

(b) Wheat

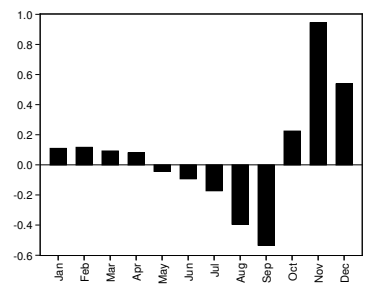

(c) Soybeans

Note: Given that inventory data are volatile and have a trend, it is not possible to measure seasonality on the raw inventory data. Instead, we compute the deviation from the long-term trend ((raw inventory - trend)/trend) using the Hodrick-Prescott filter and fit monthly dummies to this deviation to find the seasonality. The inventory data are weekly CBOT inventory data available in elevators accepted for delivery in Chicago and Toledo.

Unfortunately, inventory data are subject to potential data errors. Strictly-Chicago numbers ignore availabilities that may be quite nearby, so that they would be noisy proxies of a true variable. But numbers for a wider area are probably noisy too since they ignore the location issues: corn 200 miles away is not the same as corn delivered in the Chicago harbor. Additionally, we have to account for potential recording errors. Finally, we have strong suspicions that the Chicago data actually lag behind the true availabilities. Figure 1 shows the monthly average of the normalized inventory for corn, wheat and soybeans in Chicago from 1986 to 2008. Clearly, the graphs indicate that inventories peak in March (corn), in September (wheat) and in November (soybeans) which is one or two months after the actual harvest times. As a result, any model including inventory levels will be subject to an error-in-variable downward bias on the coefficient. ${ }^{5}$ The variance-covariance equations are modeled as a $\operatorname{GARCH}(1,1)$ augmented by the inventory terms vector $\Xi_{I, t-1}$ :

$$
\begin{aligned}
\sigma_{I_{c b o t}, s, t}^{2}= & \delta_{I_{c b o t}, s}+\theta_{I_{c b o t}, s} \varepsilon_{s, t-1}^{2}+\lambda_{I_{c b o t}, s} \sigma_{I_{c b o t}, s, t-1}^{2} \\
& +\Phi_{I_{c b o t}, s} \Xi_{I_{c b o t}, t-1}+\eta_{I_{c b o t}, s, t}, \\
\sigma_{I_{c b o t}, f, t}^{2}= & \delta_{I_{c b o t}, f}+\theta_{I_{c b o t}, f} \varepsilon_{f, t-1}^{2}+\lambda_{I_{c b o t}, f} \sigma_{I_{c b o t}, f, t-1}^{2} \\
& +\Phi_{I_{c b o t}, f} \Xi_{I_{c b o t}, t-1}+\eta_{I_{c b o t}, f, t}, \\
\sigma_{I_{c b o t}, s f, t}= & \rho_{I_{c b o t}, s f} \sqrt{\sigma_{I_{c b o t}, s, t} \sigma_{I_{c b o t}, f, t}},
\end{aligned}
$$

\footnotetext{
${ }^{5}$ We thank dr. Carl Nelson for pointing this out.
} 
for the weekly inventory held by warehouses regular for delivery of CBOT contracts and

$$
\begin{aligned}
\sigma_{I_{q}, s, t}^{2}= & \delta_{I_{q}, s}+\theta_{I_{q}, s} \varepsilon_{s, t-1}^{2}+\lambda_{I_{q}, s} \sigma_{I_{q}, s, t-1}^{2} \\
& +\Phi_{I_{q}, s} \Xi_{I_{q}, t-1}+\eta_{I_{q}, s, t}, \\
\sigma_{I_{q}, f, t}^{2}= & \delta_{I_{q}, f}+\theta_{I_{q}, f} \varepsilon_{f, t-1}^{2}+\lambda_{I_{q}, f} \sigma_{I_{q}, f, t-1}^{2} \\
& +\Phi_{I_{q}, f} \Xi_{I_{q}, t-1}+\eta_{I_{q}, f, t}, \\
\sigma_{I_{q}, s f, t}= & \rho_{I_{q}, s f} \sqrt{\sigma_{I_{q}, s, t} \sigma_{I_{q}, f, t}},
\end{aligned}
$$

for the quarterly state-by-state on- and off-farm inventory from the USDA survey.

\subsubsection{The asymmetric basis of Lien and Yang (2008)}

To ensure our results are comparable to earlier findings, we also use the asymmetric basis specification of Lien and Yang (2008). As discussed above, the Lien and Yang (2008) specification for scarcity/abundance has a number of advantages. The basis is readily available and not subject to data errors. Moreover, it has been shown in the past to correlate with inventory levels.

We test the following variance-covariance model:

$$
\begin{aligned}
\sigma_{\text {basis }, \mathrm{s}, t}^{2}= & \delta_{\text {basis }, s}+\theta_{\text {basis }, s} \varepsilon_{s, t-1}^{2}+\lambda_{\text {basis }, s} \sigma_{\text {basis }, s, t-1}^{2}+ \\
& \Phi_{\text {basis }, s} \Xi_{\text {basis }, t-1}+\eta_{\text {basis }, s, t}, \\
\sigma_{\text {basis }, f, t}^{2}= & \delta_{\text {basis }, f}+\theta_{\text {basis }, f} \varepsilon_{f, t-1}^{2}+\lambda_{\text {basis }, f} \sigma_{\text {basis }, f, t-1}^{2}+ \\
& \Phi_{\text {basis }, f} \Xi_{\text {basis }, t-1}+\eta_{\text {basis }, f, t}, \\
\sigma_{\text {basis }, s f, t}= & \rho_{\text {basis }, s f} \sqrt{\sigma_{\text {basis }, s, t} \sigma_{\text {basis }, f, t}} .
\end{aligned}
$$

\subsubsection{The convenience yield}

Following Ng and Pirrong, we also consider the convenience yield as a proxy for scarcity/abundance. The convenience yield, an unobservable variable, is calculated as

$$
c y_{t, T}:=\left[S_{t}+\operatorname{PV}(C, \mathbf{r}, t, T)\right]\left(1+r_{t, T}\right)-F_{t, T} .
$$

with $F_{t, T}$ the futures price at $t$ for a contract maturing at $T, S_{t}$ the current spot price, $S_{t} \times r_{t, T}$ the opportunity cost of investing in the spot market instead of the futures market 
and $\mathrm{PV}(C, \mathbf{r}, t, T)]$ the discounted costs of storage from $t$ to $T$ given interest rates $\mathbf{r}$. The convenience yield has been shown in the past to be empirically related to inventory levels, and therefore it is a promising measure for scarcity. Because it corrects for storage costs and the opportunity cost, it should actually be a more accurate reflection of scarcity/abundance than the basis.

The resulting model for estimation is:

$$
\begin{aligned}
\sigma_{c y, s, t}^{2}= & \delta_{c y, s}+\theta_{c y, s} \varepsilon_{s, t-1}^{2}+\lambda_{c y, s} \sigma_{c y, s, t-1}^{2}+ \\
& \Phi_{c y, s} \Xi_{c y, t-1}+\eta_{c y, s, t}, \\
\sigma_{c y, f, t}^{2}= & \delta_{c y, f}+\theta_{c y, f} \varepsilon_{f, t-1}^{2}+\lambda_{c y, f} \sigma_{c y, f, t-1}^{2}+ \\
& \Phi_{c y, f} \Xi_{c y, t-1}+\eta_{c y, f, t}, \\
\sigma_{c y, s f, t}= & \rho_{c y, s f} \sqrt{\sigma_{c y, s, t} \sigma_{c y, f, t}} .
\end{aligned}
$$

\subsubsection{The spot price}

As the fourth measure, we consider the spot price. Hayek (1945) wrote that producers and consumers just need the price to take rational decisions since it is a reflection of supply and demand; in line with this, Brennan (1958), Brennan (1991) and others have proposed the spot price as a sufficient statistic for scarcity, in the sense that there should be a one-to-one relation between the spot price and the available inventories. Price data also avoid measurement issues in convenience yield and inventories. More specifically, one potentially useful feature of prices, if they are set in efficient markets, is that they should see through any shortcomings in published inventory data. Unfortunately, the spot price cannot be used as a variable since it contains a unit root. The economic counterpart to this statistical feature is that 1980 and 2008 prices may differ for reasons unconnected with scarcity, eg. general inflation, or changes in technology, or shifts in demand. Instead, we take the deviation of the spot price from its Hodrick-Prescott trend. ${ }^{6}$

\footnotetext{
${ }^{6}$ The smoothness parameter of the Hodrick-Prescott filter is set to 270400 , equivalent to 1880 on a quarterly basis, that is, quite a flexible trend.
} 
The resulting model is:

$$
\begin{aligned}
& \sigma_{s p o t, s, t}^{2}=\delta_{s p o t, s}+\theta_{\text {spot }, s} \varepsilon_{s, t-1}^{2}+\lambda_{\text {spot }, s} \sigma_{\text {spot }, s, t-1}^{2}+ \\
& \Phi_{\text {spot }, s} \Xi_{\text {spot }, t-1}+\eta_{\text {spot }, s, t}, \\
& \sigma_{s p o t, f, t}^{2}=\delta_{s p o t, f}+\theta_{\text {spot }, f} \varepsilon_{f, t-1}^{2}+\lambda_{\text {spot }, f} \sigma_{\text {spot }, f, t-1}+ \\
& \Phi_{s p o t, f} \Xi_{s p o t, t-1}+\eta_{s p o t, f, t}, \\
& \sigma_{\text {spot }, s f, t}=\rho_{s f} \sqrt{\sigma_{\text {spot }, s, t} \sigma_{\text {spot }, f, t}} .
\end{aligned}
$$

\subsubsection{The combination of the above}

Finally, we consider the combination of actual inventory levels, the basis, the convenience yield and the spot price.

\subsubsection{Expected coefficients of the scarcity/abundance measures}

As predicted by Fama and French (1988) and further analyzed by Ng and Pirrong (1994), we expect scarcity to increase the instantaneous volatility of spot and futures returns in the short term and to decrease the instantaneous correlation. They test their hypothesis on daily data and find that their expectations hold. Given the results of Kogan, Livdan and Yaron (2008) and Lien and Yang (2008), we also expect abundance to increase the instantaneous volatility of spot and futures returns. These authors also test their model on daily data and find the expected signs for the coefficients of the asymmetric basis.

We also want to know to what extent the volatility impact of scarcity/abundance described by the above authors is a short-term phenomenon. Commodity markets may have found a new equilibrium in a matter of hours or days, not weeks. As a result, it is possible that our weekly and monthly data show mixed results.

\subsection{Comparing the performance of two competing hedging strategies}

Traditionally, to compare the performance of two hedging strategies $H S_{1}$ and $H S_{2}$, researchers compare the variance or the utility that can be obtained when agents hedge using $H S_{1}$ instead of $\mathrm{HS}_{2}$. To test the statistical significance of the variance reduction obtained from using 
the strategy that includes the asymmetric basis in the GARCH model, Lien and Yang (2008) use the non-parametric squared-rank test described by Conover (1999). This measure suffers from two major drawbacks. First, the non-parametric squared-rank test assumes independence of observations within sample and between samples. This is clearly not the case here. The GARCH method explicitly models dependence between observations by linking current variances to lagged ones. Moreover, the comparison of related GARCH models also calls into question the independence between samples. Second, as discussed by De Ville de Goyet (2007), it is an unconditional measure. It is not adequate to evaluate the performance of a dynamic strategy based on conditional portfolio return variances and covariances by an unconditional measure. Moreover, commodity returns typically exhibit conditional heteroscedasticity. What matters is not the average performance of a strategy but the conditional performance at a particular moment in time. A hedging strategy with a good overall performance might still perform very poorly when it matters most to the hedger.

To alleviate the above problems, we use both the unconditional Diebold and Mariano (1995) (DM) test statistic and the conditional Giacomini and White (2006) (GW) test statistic. Though both tests were derived to compare the predictive ability of two competing forecast strategies (and not the performance of two realized hedged portfolio returns), they are well suited to our application for the following reasons.

Because the conditional GW test is based on the unconditional DM test, and nests all applications of DM, we discuss only why the DM approach is relevant for comparing the hedging performance of $H S_{1}$ and $H S_{2}$. The DM approach is suited to our problem because 'in contrast to previously developed tests, a wide variety of accuracy measures can be used (in particular, the loss function need not be quadratic and need not even be symmetric), and forecast errors can be non-Gaussian, non-zero mean, serially correlated, and contemporaneously correlated' (Diebold and Mariano (1995), page 134, abstract). As such, the DM test overcomes the issues related to the non-parametric squared-rank test of Conover (1999).

Though we are not dealing with a series of forecast errors, but with a series of squared realized hedged portfolio returns, ${ }^{7}$ the flexibility of their approach allows us to use their test for our application. DM specify a very general loss differential function $d_{t} \equiv\left[g\left(e_{i t}\right)-g\left(e_{j t}\right)\right]$,

\footnotetext{
${ }^{7}$ Or the realized CRRA utilities depending on the performance measure we want to analyze.
} 
where $e_{i t}$ and $e_{j t}$ are the time-t forecast errors of strategy $i$ and $j$ respectively and $g($.$) is a$ function of the forecast error. Given that the forecast errors can have a non-zero mean, we can replace them with the realized hedged portfolio returns of $H S_{1}$ and $H S_{2}$. Moreover, DM allow for a wide variety of loss functions $g($.$) so that we can apply the realized squared portfolio$ return for our application. ${ }^{8}$

In this paper, the DM and the GW tests are implemented as follows.

First, we perform both in-sample and out-of-sample hedging effectiveness tests. The insample observations range from $t=1, \ldots, T_{i n}$ and the out-of-sample observations range from $t=T_{\text {in }}+1, \ldots, T$. For the in-sample analysis, we estimate the bivariate GARCH equations for the full sample $t=1, \ldots, T_{i n}$ and find the conditional spot and futures price volatilities as well as the conditional covariance for each period. For the out-of-sample analysis, we update the bivariate GARCH equations each period so that the out-of-sample results are based on the most recent available information. In other words, for the out-of-sample analysis at time $t_{o s}=T_{i n}+x$, we start by estimating the GARCH equations for the period $\left[1, T_{i n}+(x-1)\right]$. Thus, we use an expanding window estimation as opposed to an moving window estimation. ${ }^{9}$

Second, we compute the time $t$ hedge ratio the hedger will use to hedge his position from $t$ to $t+1$. Different specifications can be used for the hedge ratio. Lien and Yang (2008) specify the hedge ratio as $h_{t}=\frac{\hat{\sigma}_{s f, t+1}}{\hat{\sigma}_{f, t+1}}$, the ratio of the time $t$ forecast of the covariance at $t+1$ and the variance at $t$. We prefer to compute the hedge ratio as $h_{t}=\frac{\hat{\sigma}_{s f, t}}{\hat{\sigma}_{f, t}}$, the ratio of the estimated time $t$ covariance and variance. Both methods make sense out-of-sample because they are based on time $t$ information only. However, using the first specification for the in-sample analysis will lead to better in-sample results. For the in-sample estimation, the coefficients of the bivariate GARCH equations and the conditional variance and covariance series are estimated for the full sample and cannot be considered a forecasted value based on past information. Thus, the forecasted conditional variance-covariance series at $t+1$ actually fully reflect information up

\footnotetext{
${ }^{8}$ Please note that we are not dealing with forecast errors here as in DM. For each scarcity measure defined above, we forecast an optimal time $t$ hedge ratio to hedge our portfolio from $t$ to $t+1$. Based on that hedge ratio, we compute the realized portfolio returns for each strategy and compare the performance for each model. As such, we do not compare forecasts with actual values, but we compare which hedge ratio leads to the best portfolio performance.

${ }^{9}$ In a previous version of the paper, with a slightly different GARCH specification, we also tested a moving window estimation. The main conclusions of the paper are not affected by the estimation window.
} 
to time $t+1$.

Third, we calculate the realized hedged portfolio returns as $r_{p, t}=r_{s, t}-h_{t-1} r_{f, t}$. Based on the realized hedged portfolio returns, we compute the loss function for the DM and the GW tests. We define a minimum-variance utility-based loss function and a constant relative risk aversion utility-based loss function:

$$
\begin{aligned}
l_{\min V, i j, t} & =\left(r_{p, i, t}-E\left(r_{p, i, t}\right)\right)^{2}-\left(r_{p, j, t}-E\left(r_{p, j, t}\right)\right)^{2} \\
l_{C R R A, i j, t} & =\frac{1}{1-\gamma}\left(W_{t-1}+r_{p, i, t} * n\right)^{(1-\gamma)}-\frac{1}{1-\gamma}\left(W_{t-1}+r_{p, j, t} * n\right)^{(1-\gamma)}
\end{aligned}
$$

where $(i, j)$ stands for hedging strategy $i$ and $j, E\left(r_{p, i, t}\right)$ is taken as the mean realized portfolio return, $\gamma$ is the relative risk aversion parameter, $W$ is the wealth of the investor and $n$ is the number of bushels for one contract. ${ }^{10}$ Each period, we compare the realized utility the hedger would have gained (lost) by choosing strategy $H S_{1}$ over strategy $H S_{2}$. Please note that, except for the minimum-variance hedge ratio, ${ }^{11}$ the loss function is not an expected utility calculation in the strict sense of the word. Ideally, we would look for the optimal hedge ratio given the hedger's utility function and try to estimate the cost of using a suboptimal hedge ratio (such as GARCH or OLS) in the tradition of Lence (1996). Here, we test, ex post, whether a hedger with a non-minimum variance utility would have gained (or lost) from using $H S_{1}$ over $H S_{2}$.

Last, we define the DM and the GW test. The DM approach tests the null hypothesis of equal unconditional hedging effectiveness. As such,

$$
H_{0, D M}: E\left[l_{k, i j, t}\right]=0
$$

Under $H_{0, D M}$, the statistic

$$
D M \equiv \frac{\sqrt{T} \cdot \bar{l}_{k, i j}}{\sqrt{L \hat{R} V\left(l_{k, i j, t}\right)}} \rightarrow N(0,1),
$$

where $\bar{l}_{k, i j}$ is the mean of the loss function, subscript $k$ stands for minimum-variance or CRRA utility, $T$ is the number of observations and $L \hat{R} V\left(l_{k, i j, t}\right)$ is an estimate of the long-run variance of $l_{k, i j, t}$. To simplify matters, the DM statistic can actually be written as the $t$-statistic in a

\footnotetext{
${ }^{10}$ We arbitrarily set wealth at $\$ 1000$. One contract is 5000 bushels.

${ }^{11}$ see Kroner and Sultan (1993) for the derivation of the MVHR from the mean-variance expected utility function when futures prices are expected to follow a martingale.
} 
regression with Newey-West standard errors of $l_{k, i j, t}$ on a constant. The GW approach tests the null hypothesis of equal conditional hedging effectiveness:

$$
H_{0, G W}: E\left[l_{k, i j, t} \mid I_{t-1}\right]=0 .
$$

To test the GW null hypothesis, $H_{0, G W}$ has to be rewritten. We derive a set of unconditional moment conditions from $H_{0, G W}$. Given $z_{t-1}$, a $q \times 1$ vector included in the information set and $Z_{t} \equiv z_{t-1} l_{k, i j, t}$, the law of total expectations implies that $H_{0, G W}$ can be rewritten as

$$
H_{0, z}: E\left[Z_{t}\right]=0
$$

which says that performance differences are uncorrelated with any variable $z_{t}$. Giacomini and White (2006) construct a test of $H_{0, z}$ against the two-sided alternative

$$
H_{1, z}: E\left[Z_{t}\right]^{\prime} E\left[Z_{t}\right]>0,
$$

based on the statistic

$$
G W \equiv T \bar{Z}^{\prime} \hat{\sum}^{-1} \bar{Z}
$$

where $\bar{Z}$, the mean of $Z_{t}$, is a $q \times 1$ vector and $\hat{\sum}$ is a $q \times q$ matrix estimating the variance of $Z_{t}$. Under $H_{0, z}, G W \rightarrow \chi_{q}^{2}$.

We choose the variables $z_{t-1}$ from the information set that have potential explanatory power for predicting the loss function $l_{k, i j, t}$. More specifically, we take

$$
z_{t-1} \equiv\left(1, \Delta s_{t-1}, \Delta f_{t-1}, l_{k, i j, t-1}, c y_{t-1}, \Delta s_{t-1} \Delta f_{t-1}\right) \prime
$$

As described in Giacomini and White (2006), the GW statistic can easily be computed as $T_{\text {out }} R^{2}$, where $T_{\text {out }}$ is the number of out-of-sample observations and $R^{2}$ is the uncentered square multiple correlation coefficient for the artificial regression $\iota=Z \gamma+\epsilon$ with $\iota$ a vector of ones.

\section{Data, Sample Periods and Descriptive Statistics}

The model is estimated using daily, weekly and monthly CBOT futures data for corn and wheat between 1885:01 and 1935:52, ${ }^{12}$ and for corn, wheat and soybeans between 1989:01 and 2008:35.

\footnotetext{
${ }^{12}$ Please note that we exclude data from 1917 to 1920 because trading restrictions and price ceilings were in place in the aftermath of the first World war.
} 
The recent data have been downloaded from Datastream. Published spot prices nowadays are the prices paid at the elevators (before 2000 for corn and soybeans) or barge loading locations along the Illinois river (after 2000 for corn and soybeans) when a futures contract is exercised. As such, there is a location differential between the spot and futures prices. Moreover, spot prices are not quoted on a central financial market and are typically illiquid. Therefore we follow the common practice in the literature and use the nearest futures as the spot price and the deferred futures as the futures price for the recent sample. The prices of the nearest futures and the deferred futures contracts are the daily settlement prices reported by The Chicago Board of Trade.

The pre-WWII data have been manually collected from the CBOT microfilms. For the preWWII sample, we use actual spot prices and the nearest futures prices to perform the analysis. The spot price in the older sample is of better quality than in the modern sample. The spot price used to be the daily settlement price from an organized (and very liquid) exchange, the Chicago Board of Trade (CBOT), unlike the recent spot prices. Moreover, in the past, most of the warehouses were in Chicago, and all deliveries were centralized there. Inventory levels in Chicago accounted for a far higher proportion of nationwide totals than they do nowadays. The spot and futures prices in the microfilms are quoted daily in separate tables devoted entirely to futures trading: therefore, we feel safe in assuming that the spot prices quoted are for qualities deliverable on the futures contract.

A continuous futures price series is constructed by rolling over nearest-to-maturity contracts. Please note that contracts are rolled over on the last day before the delivery month of the nearest to maturity contract, as is commonly done in the literature, to avoid problems related to the unknown delivery date and low liquidity in the delivery month. Simple returns are calculated from the spot and futures price series, and the basis is computed as the difference between the spot and futures price. To avoid distorted returns due to the rollover of nearest-to-maturity futures contracts, returns are always calculated from the same maturity contract. For example, at time $t$, with time $t$ being the last quote before rollover of the may contract to the july contract, the return is computed as $\frac{f_{\text {may }, t-f_{\text {may }, t-1}}}{f_{\text {may }, t-1}}$ and at time $t+1$ the return is equal to $\frac{f_{\text {jul } y, t+1}-f_{\text {july }, t}}{f_{\text {july,t }}}$ and not $\frac{f_{\text {july,t+1 }}-f_{\text {may }, t}}{f_{\text {may }, t}}$.

Weekly Chicago inventory data and storage costs have been collected from the microfilms for the pre-WWII sample and have been supplied by the CBOT for the recent sample. The 
recent Chicago inventory data pertain to inventory levels available in elevators cleared for delivery by the CBOT. Unfortunately, hey are an inaccurate reflection of real inventory levels available in the larger Chicago region, a more logical unit of measurement when it comes to scarcity or abundance. Therefore, we also use quarterly inventory data available from the USDA. These are compiled from a quarterly survey and represent on- and off-farm inventory for each state in the US. We have chosen inventory levels for Illinois and Ohio so as to cover the area around Chicago and the area around Toledo, the two main delivery centers for CBOT contracts. The storage rate is the premium paid by holders of a delivery certificate as defined by the CBOT futures contract. For the interest rate, we use the 3-Month libor for the recent data and the 3-Month interest rate provided by the NBER for the 1885-1935 sample.

Though the main results of course pertain to the recent sample, the older sample is useful for the following reasons. First, the pre-WWII sample allows us to perform sensitivity analysis and to analyze whether and how market conditions prevailing in different times influence the optimal formulation of scarcity in the hedge ratio formulas. As discussed in the introduction, prior results on hedge ratios are always limited by the sample under consideration. To avoid this, we use the most comprehensive dataset we could find. The pre-WWII data start from 1885 because that is when the CBOT started recording futures prices in their annual books. Though the microfilms contain good data until 1950, we stop in 1935 to avoid issues due to the outbreak of World War II. We split the pre-WWII data into two subsamples. The first sample runs from $1 / 31 / 1885$ to $12 / 30 / 1916$ and the second sample runs from $1 / 1 / 1921$ to $11 / 08 / 1935$. The period between 1917 to 1921 is excluded because prices during the first world war were characterized by price ceilings and trading restrictions. The in-sample results are based on the total subsample, the out-of-sample results are based on one-fourth of the data, i.e. the period $1 / 16 / 1909$ to $12 / 30 / 1916$ for the first subsample and the period $1 / 30 / 1932$ to $11 / 08 / 1935$ for the second subsample.

For the contemporary data, we analyze four different samples: the first sample pertains to all data from $1 / 04 / 1989$ to $9 / 02 / 2008$, the second sample to the period 1/04/1989 to $12 / 30 / 1999$, the third sample to the period $1 / 05 / 2000$ to $9 / 02 / 2008$, and the fourth sample to the period 1/04/1989 to 12/30/2004. The data start in 1989 to avoid contaminating the results with the government stockholding programs in the mid 1980's. Before 1989, the USDA ran up a huge volume of stocks and provided incentives to farmers to store. Therefore, the 
results would not be representative. After the drought of 1988, the government sold off most of the stocks and changed its policy. The second and the third sample have been chosen to reflect changes in the delivery system of corn and soybeans. Prior to the 2000 March contract, Chicago and Toledo were the only delivery location, with Toledo the main market for delivery. From the March 2000 contract on, the delivery system was changed from a storage certificate (for storage in a warehouse regular for delivery) to a shipping certificate (a call on the shipping throughput of a firm that barges grain down the Illinois and Mississippi rivers). While before the corn and soybean March 2000 contract, the storage certificate still represented actual storage in one of the warehouses regular for delivery, this link has now disappeared. If a holder of a shipping certificate demands delivery, the barge company has three days to buy grain and barge it down the river to the prespecified location. The fourth sample, lastly, stops in 2004 to check the impact of issues related to convergence problems in agricultural markets in the last few years and of the corn fuel subsidies.

Table 1 provides descriptive statistics of the spot and futures returns. The table shows large differences between spot and futures returns and basis levels between the subsamples. For the contemporary data, we see that mean spot returns are much higher, the mean futures returns are much lower while the basis is larger in absolute value between 2000 and 2008 than between 1989 and 1999. This could be the result of the special circumstances in agricultural spot and futures markets since 2006. For the pre-WWII data, the mean spot and futures returns are larger while the basis is smaller between 1885 and 1916 than between 1921 and 1935. Interestingly, the average basis in the recent period is negative, suggesting that the futures markets either reflect full carrying charges or are in contango on average. However, the pre-WWII markets seem to have been in backwardation on average since spot prices exceeded futures prices. To get a better feel of the underlying data, Figure 2 shows the evolution of nominal spot and futures prices, and of the basis, for the periods under consideration.

\section{Empirical Results}

We split the results in three main categories.

First, we test whether the results of Lien and Yang (2008) are robust for different sample periods, hedging horizons and utility functions. In other words, we compare the hedging 
Figure 2: Evolution of nominal weekly spot and futures prices, and basis, for corn, wheat and soybeans.

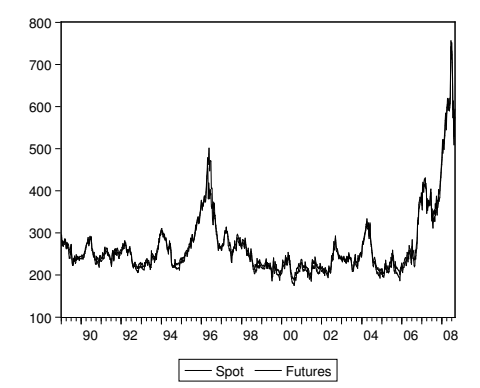

(a) Corn prices: 1985-2008

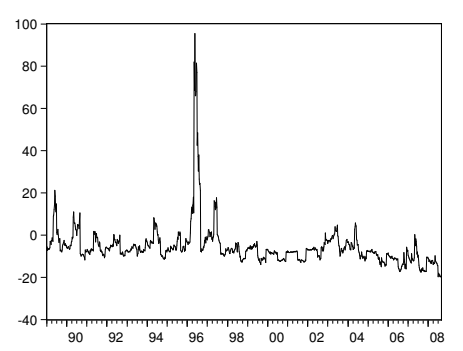

(d) Corn basis: 1985-2008

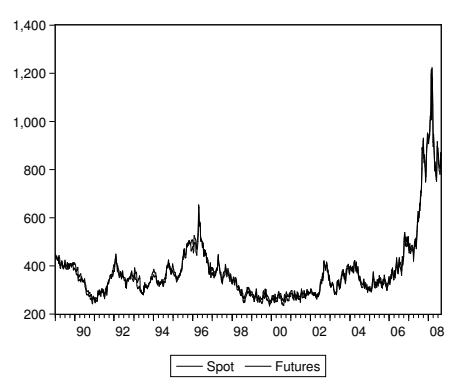

(b) Wheat prices: 1985-2008

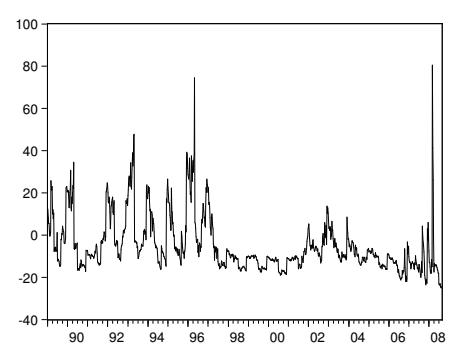

(e) Wheat basis: 1985-2008

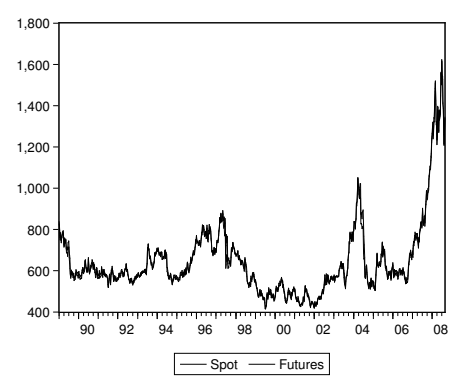

(c) Soybeans prices: 1985-2008

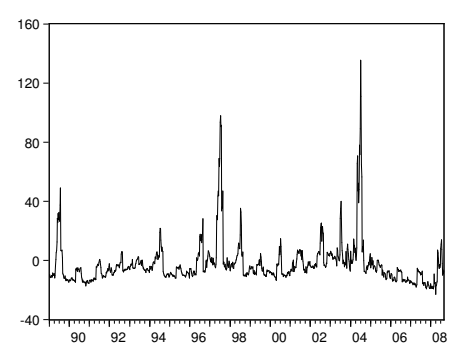

(f) Soybeans basis: 1985-2008

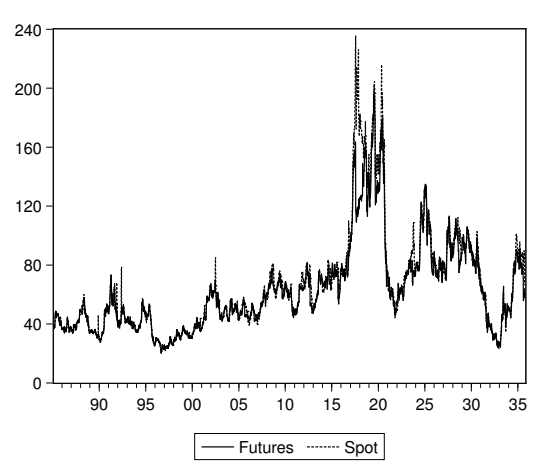

(g) Corn prices: 1885-1935

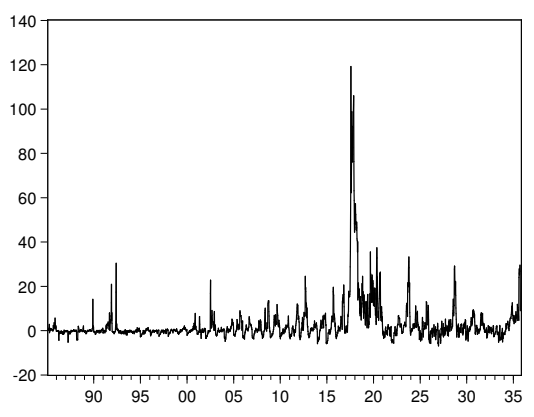

(i) Corn basis: 1885-1935

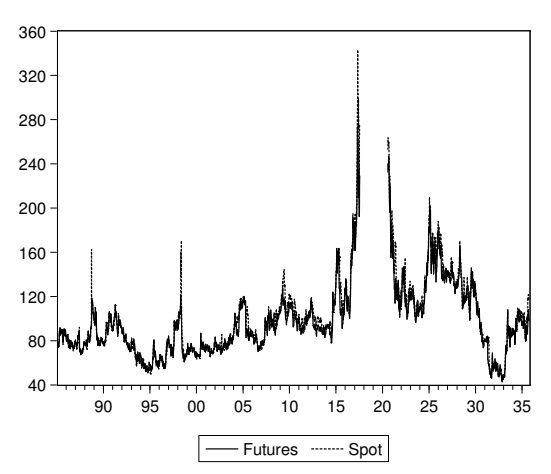

(h) Wheat prices: 1885-1935

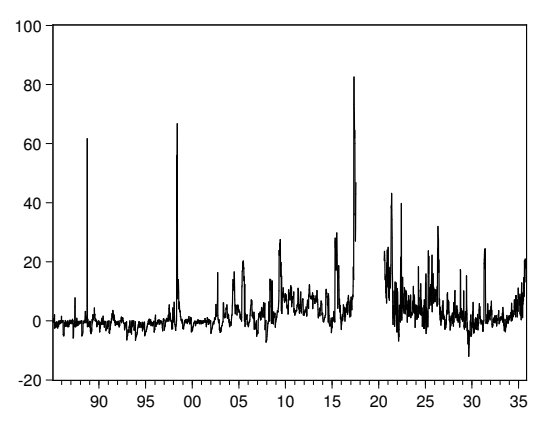

(j) Wheat basis: 1885-1935 
Table 1: Descriptive statistics of spot returns, futures returns and basis for all samples

\begin{tabular}{|c|c|c|c|c|c|c|c|c|c|}
\hline \multirow{3}{*}{ Commodity } & \multicolumn{7}{|c|}{ Panel A: Weekly sample, 1989-2008 } & \multirow{2}{*}{\multicolumn{2}{|c|}{$\overline{~ 1 / 4 / 1989-12 / 29 / 2004}$}} \\
\hline & \multirow[t]{2}{*}{ Variable } & \multicolumn{2}{|c|}{$\overline{1 / 4 / 1989-8 / 27 / 2008}$} & \multicolumn{2}{|c|}{$\overline{1 / 4 / 1989-12 / 29 / 1999}$} & \multicolumn{2}{|c|}{ 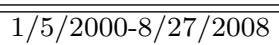 } & & \\
\hline & & Mean & Std. & Mean & Std. & Mean & Std. & Mean & Std. \\
\hline \multirow[t]{3}{*}{ Corn } & $r_{s}$ & -0.107 & 3.177 & -0.143 & 2.790 & -0.062 & 3.613 & -0.183 & 2.850 \\
\hline & $r_{f}$ & -0.061 & 3.093 & -0.109 & 2.782 & -0.000 & 3.451 & -0.146 & 2.804 \\
\hline & basis & -5.613 & 9.908 & -2.818 & 11.908 & -9.162 & 4.516 & -4.145 & 10.302 \\
\hline \multirow[t]{3}{*}{ Wheat } & $r_{s}$ & -0.066 & 3.422 & -0.141 & 2.920 & 0.030 & 3.971 & -0.155 & 3.083 \\
\hline & $r_{f}$ & 0.003 & 3.263 & -0.100 & 2.757 & 0.133 & 3.810 & -0.101 & 2.908 \\
\hline & basis & -4.904 & 12.972 & -0.706 & 14.417 & -10.236 & 8.213 & -3.109 & 12.921 \\
\hline \multirow[t]{3}{*}{ Soybeans } & $r_{s}$ & 0.059 & 2.957 & -0.084 & 2.629 & 0.240 & 3.322 & -0.005 & 2.783 \\
\hline & $r_{f}$ & 0.056 & 2.942 & -0.119 & 2.656 & 0.278 & 3.258 & -0.019 & 2.775 \\
\hline & basis & -2.525 & 14.893 & -2.676 & 13.860 & -2.332 & 16.123 & -0.777 & 15.723 \\
\hline \multicolumn{10}{|c|}{ Panel B: Weekly sample, 1885-1935 } \\
\hline \multirow[t]{2}{*}{ Commodity } & Variable & $\overline{1 / 1 / 31 / 1 \zeta}$ & $2 / 30 / 1916$ & 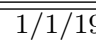 & $0 / 5 / 1935$ & & & & \\
\hline & & Mean & Std. & Mean & Std. & & & & \\
\hline \multirow[t]{3}{*}{ Corn } & $r_{s}$ & 0.143 & 4.137 & 0.090 & 4.552 & & & & \\
\hline & $r_{f}$ & 0.118 & 3.506 & 0.078 & 4.693 & & & & \\
\hline & basis & 0.734 & 3.297 & 2.189 & 5.630 & & & & \\
\hline \multirow[t]{3}{*}{ Wheat } & $r_{s}$ & 0.129 & 4.063 & 0.072 & 5.061 & & & & \\
\hline & $r_{f}$ & 0.107 & 3.414 & 0.018 & 4.130 & & & & \\
\hline & basis & 1.843 & 5.626 & 3.951 & 6.614 & & & & \\
\hline
\end{tabular}

Note: The weekly spot and futures return data are based on simple percentage returns. The basis is defined as basis $=S-F$. The quoted spot price is the actual spot price and the nearest futures price for the pre-WWII sample and the recent sample respectively; the quoted futures price is the nearest futures price and the deferred futures price for the for the pre-WWII sample and the recent sample respectively.

performance of the asymmetric basis model to that of the simple GARCH $(1,1)$ model and the OLS model.

Second, we discuss the sign and the significance of the scarcity variables coefficients for each subsample and each data frequency. More specifically, as briefly discussed in Section 1.1, for each scarcity model (basis, cy, spot, $I_{q}$ and $\left.I_{c b o t}\right),{ }^{13}$ we compare the in-sample AIC, SIC and HQ information criteria of including three alternative variable combinations in the error correction term of the bivariate $\operatorname{GARCH}(1,1)$ model: (i) two variables are included to account for the asymmetric effect, eg. for the basis this yields both $\max ($ basis, 0$)$ and $\min ($ basis, 0$)$ as variables; (ii) one variable is included to account for scarcity, eg. for the basis this yields $\max ($ basis, 0$)$ as a variable; and (iii) the base variable itself is included, eg. for the basis this yields the basis.

We then show the sign and the significance of the coefficients for the winning model, and also use this model as the basis for the out-of-sample hedging performance analysis. The

\footnotetext{
${ }^{13}$ Please note that, for the daily data, we only look at the basis and the cy model since inventory data do not exist at this frequency.
} 
information criteria tables are provided in appendix for the interested reader but are not discussed in the main text.

Last, we analyze whether the alternative scarcity/abundance measures we introduce outperform the asymmetric basis model, the simple $\operatorname{GARCH}(1,1)$ model and the OLS model.

\subsection{The asymmetric effect documented by Lien and Yang (2008) revisited}

In their paper on the asymmetric effect of the basis on hedging performance, Lien and Yang (2008) document across-the-board improvements in daily hedging effectiveness for a wide range of storable commodities. Their results stand both in- and out-of-sample. For corn and soybeans, they find that the asymmetric basis model outperforms the GARCH(1,1) model and the OLS model both in- and out-of-sample between 1990 and 1999. The results are less clear between 1980 and 1989 where the asymmetric basis model is outperformed in-sample but is more effective out-of-sample.

We test whether the results of Lien and Yang (2008) are robust in terms of sample period and hedging horizon. ${ }^{14}$ First, we compare the hedging performance of the basis model (as defined in Section 3) with that of the $\operatorname{GARCH}(1,1)$ model and the OLS model for the samples 1989-2008, 1989-1999, 2000-2008 and 1989-2004. We also analyze the hedging performance of the above models for the pre-WWII data. We choose these periods because they refer to specific conditions in storable agricultural markets that could affect results. ${ }^{15}$ Apart from looking at different sample periods, we also use longer out-of-sample periods than Lien and Yang (2008): one-fourth of the total subsamples, i.e. 2 years to 4 years, pertains to out-of-sample results instead of just one year of data. Second, we study whether the results are robust to the hedging horizon. A priori, we expect the basis model to perform better for a daily hedging horizon than for a weekly or monthly hedging horizon. Shocks to the system are typically short-lived and should be incorporated rather quickly in prices and volatility dynamics when markets are efficiently acting upon information. Therefore, changes in the basis are likely to have a stronger

\footnotetext{
${ }^{14}$ Please note that we use a slightly different GARCH estimation model than Lien and Yang (2008). While they use a dynamic conditional correlation GARCH model, we use a constant conditional correlation GARCH model.

${ }^{15}$ See Section 2 supra for a more detailed explanation of the sample choice.
} 
effect on the price of tomorrow than one week or one month from now.

Table 2 shows the ranking of the basis model, the GARCH(1,1) model and the OLS model in terms of hedging performance based on a minimum-variance utility function and the Diebold and Mariano test statistic. Tables 3 and 4 give the significance level of the difference in hedging performance according to the unconditional Diebold and Mariano test statistic and the conditional Giacomini and White test statistic respectively. Finally, Table 5 ranks the basis model, the GARCH $(1,1)$ model and the OLS model in terms of hedging performance based on a CRRA utility function and the Diebold and Mariano test statistic.

The results indicate that minimum-variance hedge ratios computed using the basis model perform relatively well for contemporary corn both in- and out-of-sample at the daily and weekly hedging horizon. Moreover, we find that the difference in hedging performance is often significant at the daily frequency both using the unconditional Diebold and Mariano statistic and the conditional Giacomini and White statistic. At the weekly and monthly level however, differences in the hedging performance of the different models are no longer significant, supporting the hypothesis that the biggest impact on hedging performance occurs for highfrequency data, not low-frequency data. The above results however do not stand when the hedging performance is measured for agents with a CRRA utility function.

For the recent wheat and soybeans data, we do not find evidence that the basis model leads to better hedging performance than the OLS and the $\operatorname{GARCH}(1,1)$ model. The rankings differ a lot depending on the sample period, the hedging horizon and the utility function. Again, we find significant differences of hedging performance, both conditionally and unconditionally, mainly for the daily hedging horizon.

Finally, we find that before the second World War, the OLS model consistently and significantly outperforms the basis model in terms of hedging performance.

Overall, we cannot confirm that the asymmetric effect documented by Lien and Yang (2008) is robust to the sample period, the hedging horizon and alternative utility functions.

\subsection{Scarcity/abundance and its effect on storable commodity price volatility}

Table 6, Table 7 and Table 8 show the effects of the alternative scarcity/abundance measures on the daily, weekly and monthly spot and futures price volatility of corn, wheat and oats 
Table 2: The ranking of minimum variance hedging performance based on the Diebold and Mariano test statistic, comparison of the asymmetric basis model with the simple OLS-model and the GARCH(1,1)-model. Daily, Weekly and Monthly horizon.

\begin{tabular}{|c|c|c|c|c|c|c|c|c|c|c|c|c|}
\hline & \multicolumn{8}{|c|}{ Contemporary data } & \multicolumn{4}{|c|}{ Pre-WWII data } \\
\hline & \multicolumn{4}{|c|}{ In-sample } & \multicolumn{4}{|c|}{ Out-of-sample } & \multicolumn{2}{|c|}{ In-sample } & \multicolumn{2}{|c|}{ Out-of-sample } \\
\hline & all & s1 & s2 & s3 & all & s1 & s2 & s3 & s1 & s2 & s1 & s2 \\
\hline \multicolumn{13}{|c|}{ 1. Daily hedging horizon } \\
\hline \multicolumn{13}{|c|}{ Panel A: Corn } \\
\hline basis & 1 & 2 & 2 & 1 & 1 & 1 & 1 & 1 & 3 & 2 & 3 & 2 \\
\hline garch & 3 & 3 & 3 & 3 & 2 & 2 & 3 & 2 & 2 & 3 & 2 & 3 \\
\hline ols & 2 & 1 & 1 & 2 & 3 & 3 & 2 & 3 & 1 & 1 & 1 & 1 \\
\hline \multicolumn{13}{|c|}{ Panel B: Wheat } \\
\hline basis & 3 & 3 & 3 & 3 & 3 & 2 & 3 & 1 & 2 & 2 & 2 & 2 \\
\hline garch & 2 & 2 & 2 & 2 & 1 & 1 & 2 & 2 & 3 & 3 & 3 & 3 \\
\hline ols & 1 & 1 & 1 & 1 & 2 & 3 & 1 & 3 & 1 & 1 & 1 & 1 \\
\hline \multicolumn{13}{|c|}{ Panel C: Soybeans } \\
\hline basis & 2 & 2 & 1 & 2 & 1 & 2 & 1 & 2 & - & - & - & - \\
\hline garch & 3 & 3 & 3 & 3 & 3 & 3 & 2 & 3 & - & - & - & - \\
\hline ols & 1 & 1 & 2 & 1 & 2 & 1 & 3 & 1 & - & - & - & - \\
\hline \multicolumn{13}{|c|}{ 2. Weekly hedging horizon } \\
\hline \multicolumn{13}{|c|}{ Panel A: Corn } \\
\hline basis & 1 & 1 & 2 & 1 & 1 & 1 & 2 & 1 & 2 & 2 & 3 & 3 \\
\hline garch & 3 & 3 & 3 & 3 & 2 & 2 & 3 & 2 & 3 & 3 & 2 & 2 \\
\hline ols & 2 & 2 & 1 & 2 & 3 & 3 & 1 & 3 & 1 & 1 & 1 & 1 \\
\hline \multicolumn{13}{|c|}{ Panel B: Wheat } \\
\hline basis & 2 & 3 & 1 & 2 & 1 & 3 & 3 & 1 & 2 & 3 & 2 & 3 \\
\hline garch & 3 & 2 & 2 & 3 & 3 & 1 & 2 & 2 & 3 & 2 & 3 & 2 \\
\hline ols & 1 & 1 & 3 & 1 & 2 & 2 & 1 & 3 & 1 & 1 & 1 & 1 \\
\hline \multicolumn{13}{|c|}{ Panel C: Soybeans } \\
\hline basis & 1 & 1 & 2 & 1 & 2 & 2 & 1 & 2 & - & - & - & - \\
\hline garch & 3 & 2 & 3 & 3 & 3 & 3 & 2 & 3 & - & - & - & - \\
\hline ols & 2 & 3 & 1 & 2 & 1 & 1 & 3 & 1 & - & - & - & - \\
\hline \multicolumn{13}{|c|}{ 3. Monthly hedging horizon } \\
\hline \multicolumn{13}{|c|}{ Panel A: Corn } \\
\hline basis & 1 & 3 & 3 & 2 & 3 & 3 & 3 & 2 & - & - & - & - \\
\hline garch & 3 & 2 & 1 & 3 & 1 & 2 & 1 & 1 & - & - & - & - \\
\hline ols & 2 & 1 & 2 & 1 & 2 & 1 & 2 & 3 & - & - & - & - \\
\hline \multicolumn{13}{|c|}{ Panel B: Wheat } \\
\hline basis & 2 & 3 & 3 & 1 & 3 & 3 & 1 & 2 & - & - & - & - \\
\hline garch & 3 & 1 & 1 & 2 & 2 & 1 & 3 & 3 & - & - & - & - \\
\hline ols & 1 & 2 & 2 & 3 & 1 & 2 & 2 & 1 & - & - & - & - \\
\hline \multicolumn{13}{|c|}{ Panel C: Soybeans } \\
\hline basis & 1 & 3 & 1 & 1 & 1 & 2 & 3 & 1 & - & - & - & - \\
\hline garch & 3 & 1 & 2 & 3 & 3 & 1 & 1 & 3 & - & - & - & - \\
\hline ols & 2 & 2 & 3 & 2 & 2 & 3 & 2 & 2 & - & - & - & - \\
\hline
\end{tabular}

Notes: 1 . The sample periods for the contemporary data are defined by ais, s1is, s2is, s3is for the in-sample results and by aos, s1os, s2os Notes: 1. The sample periods for the contemporary data are defined by ais, s1is, s2is, s3is for the in-sample results and by aos, s1os, s2os
and s3os for the out-of-sample results. More specifically, ais stands for the sample from January, 4, 1989 to October, 1,2003 ; s1is stands for and s3os for the out-of-sample results. More specifically, ais stands for the sample from January, 4, 1989 to October, 1, 2003; slis stands for the sample from January, 4, 1889 to March, 26, 1997; s2is stands for the sample from January, 5, 2000 to July, 5, 2006; s3is stands for the sample from January, 4, 1989 to December, 27, 2000; aos stands for the sample from October, 8, 2003 to September, 2, 2008; s1os stands for the sample from April, 2, 1997 to December, 29, 1999; s2os stands for the sample from July, 12, 2006 to September, 2, 2008; s3os stands for the sample from January, 3, 2001 to December, 30, 2004.

The sample periods for the pre-WWII data are defined by s1is, s2is for the in-sample results and by s1os, s2os for the out- of-sample results. More specifically, s1is stands for the sample from January, 31, 1885 to January, 9, 1909; s2os stands for the sample from January, 1 , 1921 to January, 23, 1932; s1os stands for the sample from January, 16, 1909 to December, 31, 1916; s2os stands for the sample from January, 30, 1932 to October, 5, 1935 .

2. The performance is ranked according to the number of times one model beats all other models. 
Table 3: Significance of difference in minimum-variance hedging performance based on the Diebold and Mariano test statistic, comparison of the asymmetric basis model with the simple OLS-model and the GARCH(1,1)-model. Daily, Weekly and Monthly horizon.

\begin{tabular}{|c|c|c|c|c|c|c|c|c|c|c|c|c|}
\hline & \multicolumn{8}{|c|}{ Contemporary data } & \multicolumn{4}{|c|}{ Pre-WWII data } \\
\hline & \multicolumn{4}{|c|}{ In-sample } & \multicolumn{4}{|c|}{ Out-of-sample } & \multicolumn{2}{|c|}{ In-sample } & \multicolumn{2}{|c|}{ Out-of-sample } \\
\hline & all & s1 & s2 & s3 & all & s1 & $\mathrm{s} 2$ & s3 & s1 & $\mathrm{s} 2$ & s1 & $\mathrm{s} 2$ \\
\hline \multicolumn{13}{|c|}{ 1. Daily hedging horizon } \\
\hline \multicolumn{13}{|c|}{ Panel A: Corn } \\
\hline garch & $\mathrm{ns}$ & ns & $* *$ & $\mathrm{~ns}$ & $*$ & ns & $\mathrm{ns}$ & $* *$ & ns & $* *$ & $*$ & $* *$ \\
\hline ols & $* *$ & ns & ns & ns & $* * *$ & $* * *$ & ns & $* * *$ & ns & $* * *$ & $* *$ & ns \\
\hline \multicolumn{13}{|c|}{ Panel B: Wheat } \\
\hline garch & $* *$ & $* *$ & ns & $* * *$ & $\mathrm{~ns}$ & $* *$ & $\mathrm{~ns}$ & ns & * & $* * *$ & $* *$ & $* * *$ \\
\hline ols & $* * *$ & $* *$ & ns & $* *$ & ns & $* * *$ & ns & ns & ns & $* * *$ & $* *$ & $* * *$ \\
\hline \multicolumn{13}{|c|}{ Panel C: Soybeans } \\
\hline garch & $*$ & * & ns & $* *$ & $* *$ & ns & $\mathrm{ns}$ & $* *$ & - & - & - & - \\
\hline ols & ns & ns & ns & $\mathrm{ns}$ & ns & ns & ns & $\mathrm{ns}$ & - & - & - & - \\
\hline \multicolumn{13}{|c|}{ 2. Weekly hedging horizon } \\
\hline \multicolumn{13}{|c|}{ Panel A: Corn } \\
\hline garch & $*$ & $* *$ & $*$ & $*$ & ns & ns & $\mathrm{ns}$ & $*$ & ns & ns & ns & ns \\
\hline ols & ns & ns & ns & ns & $*$ & ns & ns & ns & ns & ns & $* *$ & ns \\
\hline \multicolumn{13}{|c|}{ Panel B: Wheat } \\
\hline garch & $\mathrm{ns}$ & ns & ns & ns & ns & ns & $\mathrm{ns}$ & $\mathrm{ns}$ & * & ns & ns & ns \\
\hline & ns & ns & $* *$ & ns & ns & ns & ns & ns & $*$ & $* * *$ & $* *$ & $* *$ \\
\hline \multicolumn{13}{|c|}{ Panel C: Soybeans } \\
\hline garch & $\mathrm{ns}$ & ns & $\mathrm{ns}$ & $\mathrm{ns}$ & ns & ns & ns & ns & - & - & - & - \\
\hline ols & ns & ns & $\mathrm{ns}$ & ns & ns & ns & $*$ & ns & - & - & - & - \\
\hline \multicolumn{13}{|c|}{ 3. Monthly hedging horizon } \\
\hline \multicolumn{13}{|c|}{ Panel A: Corn } \\
\hline garch & $*$ & ns & $\mathrm{ns}$ & $\mathrm{ns}$ & ns & ns & $\mathrm{ns}$ & ns & - & - & - & - \\
\hline & $*$ & ns & * & ns & $\mathrm{ns}$ & ns & $\mathrm{ns}$ & $*$ & - & - & - & - \\
\hline \multicolumn{13}{|c|}{ Panel B: Wheat } \\
\hline garch & $\mathrm{ns}$ & ns & $\mathrm{ns}$ & $\mathrm{ns}$ & $*$ & ns & $*$ & $\mathrm{~ns}$ & - & - & - & - \\
\hline & ns & ns & ns & ns & $\mathrm{ns}$ & ns & ns & ns & - & - & - & - \\
\hline \multicolumn{13}{|c|}{ Panel C: Soybeans } \\
\hline garch & $\mathrm{ns}$ & $* * *$ & ns & $\mathrm{ns}$ & ns & ns & $\mathrm{ns}$ & $\mathrm{ns}$ & - & - & - & - \\
\hline & ns & ns & ns & ns & * & ns & ns & ns & - & - & - & - \\
\hline
\end{tabular}

Notes: 1. The sample periods for the contemporary data are defined by ais, s1is, s2is, s3is for the in-sample results and by aos, s1os, s2os and s3os for the out-of-sample results. More specifically, ais stands for the sample from January, 4, 1989 to October, 1, 2003; s1is stands for the sample from January, 4, 1889 to March, 26, 1997; s2is stands for the sample from January, 5, 2000 to July, 5, 2006; s3is stands for the sample from January, 4, 1989 to December, 27, 2000; aos stands for the sample from October, 8, 2003 to September, 2, 2008; s1os stands for the sample from April, 2, 1997 to December, 29, 1999; s2os stands for the sample from July, 12, 2006 to September, 2, 2008; s3os stands for the sample from January, 3, 2001 to December, 30, 2004.

The sample periods for the pre-WWII data are defined by s1is, s2is for the in-sample results and by s1os, s2os for the out- of-sample results. More specifically, s1is stands for the sample from January, 31, 1885 to January, 9, 1909; s2os stands for the sample from January, 1 , 1921 to January, 23, 1932; s1os stands for the sample from January, 16, 1909 to December, 31, 1916; s2os stands for the sample from January,

30,1932 to October, 5,1935 .
$2 . * *, * *$ and $*$ stand for significance at the $1 \%, 5 \%$ and $10 \%$ level respectively. $n s$ stands for non-significance of the Diebold and Mariano statistic. 
Table 4: Significance of difference in minimum-variance hedging performance based on the Giacomini and White test statistic, comparison of the asymmetric basis model with the simple OLS-model and the GARCH(1,1)-model. Daily, Weekly and Monthly horizon.

\begin{tabular}{|c|c|c|c|c|c|c|c|c|c|c|c|c|}
\hline & \multicolumn{8}{|c|}{ Contemporary data } & \multicolumn{4}{|c|}{ Pre-WWII data } \\
\hline & \multicolumn{4}{|c|}{ In-sample } & \multicolumn{4}{|c|}{ Out-of-sample } & \multicolumn{2}{|c|}{ In-sample } & \multicolumn{2}{|c|}{ Out-of-sample } \\
\hline & all & s1 & s2 & s3 & all & s1 & $\mathrm{s} 2$ & s3 & s1 & $\mathrm{s} 2$ & s1 & $\mathrm{s} 2$ \\
\hline \multicolumn{13}{|c|}{ 1. Daily hedging horizon } \\
\hline \multicolumn{13}{|c|}{ Panel A: Corn } \\
\hline garch & $* * *$ & $* * *$ & $\mathrm{~ns}$ & $* * *$ & ns & ns & ns & ns & ns & ns & $* * *$ & $*$ \\
\hline ols & $* * *$ & $* * *$ & ns & $* * *$ & $* * *$ & $* * *$ & ns & $* * *$ & $* * *$ & $* * *$ & $* * *$ & ns \\
\hline \multicolumn{13}{|c|}{ Panel B: Wheat } \\
\hline garch & $* * *$ & ns & ns & $* * *$ & $\mathrm{~ns}$ & $\mathrm{~ns}$ & ns & $* *$ & $*$ & $* * *$ & $* * *$ & $* * *$ \\
\hline ols & $*$ & ns & $*$ & ns & $* * *$ & $* * *$ & ns & ns & $* *$ & $* * *$ & $* *$ & $* * *$ \\
\hline \multicolumn{13}{|c|}{ Panel C: Soybeans } \\
\hline garch & $* * *$ & $* * *$ & ns & $* * *$ & ns & $* *$ & ns & $*$ & - & - & - & - \\
\hline ols & ns & ns & ns & ns & ns & ns & ns & ns & - & - & - & - \\
\hline \multicolumn{13}{|c|}{ 2. Weekly hedging horizon } \\
\hline \multicolumn{13}{|c|}{ Panel A: Corn } \\
\hline garch & $\mathrm{ns}$ & $\mathrm{ns}$ & $\mathrm{ns}$ & $\mathrm{ns}$ & ns & ns & ns & ns & ns & $*$ & ns & $*$ \\
\hline ols & ns & $* *$ & ns & $* *$ & ns & ns & ns & ns & $*$ & ns & ns & ns \\
\hline \multicolumn{13}{|c|}{ Panel B: Wheat } \\
\hline garch & ns & $\mathrm{ns}$ & $\mathrm{ns}$ & $\mathrm{ns}$ & ns & ns & ns & ns & ns & ns & ns & ns \\
\hline & $\mathrm{ns}$ & $\mathrm{ns}$ & $*$ & ns & $\mathrm{ns}$ & $*$ & ns & ns & ns & $* *$ & $* * *$ & ns \\
\hline \multicolumn{13}{|c|}{ Panel C: Soybeans } \\
\hline garch & ns & $\mathrm{ns}$ & $\mathrm{ns}$ & ns & ns & ns & ns & ns & - & - & - & - \\
\hline ols & ns & $* *$ & $\mathrm{~ns}$ & $*$ & ns & ns & ns & ns & - & - & - & - \\
\hline \multicolumn{13}{|c|}{ 3. Monthly hedging horizon } \\
\hline \multicolumn{13}{|c|}{ Panel A: Corn } \\
\hline garch & $\mathrm{ns}$ & $\mathrm{ns}$ & ns & $\mathrm{ns}$ & $\mathrm{ns}$ & ns & ns & $\mathrm{ns}$ & - & - & - & - \\
\hline & $\mathrm{ns}$ & ns & ns & ns & $\mathrm{ns}$ & ns & $\mathrm{ns}$ & ns & - & - & - & - \\
\hline \multicolumn{13}{|c|}{ Panel B: Wheat } \\
\hline \multirow{2}{*}{$\begin{array}{l}\text { garch } \\
\text { ols }\end{array}$} & $\mathrm{ns}$ & ns & ns & ns & ns & $*$ & ns & $\mathrm{ns}$ & - & - & - & - \\
\hline & ns & ns & ns & ns & ns & ns & ns & ns & - & - & - & - \\
\hline \multicolumn{13}{|c|}{ Panel C: Soybeans } \\
\hline garch & $\mathrm{ns}$ & $*$ & ns & $\mathrm{ns}$ & ns & ns & ns & $\mathrm{ns}$ & - & - & - & - \\
\hline & ns & $\mathrm{ns}$ & ns & ns & ns & ns & ns & ns & - & - & - & - \\
\hline
\end{tabular}

Notes: 1 . The sample periods for the contemporary data are defined by ais, s1is, s2is, s3is for the in-sample results and by aos, s1os, s2os and s3os for the out-of-sample results. More specifically, ais stands for the sample from January, 4, 1989 to October, 1, 2003; s1is stands for the sample from January, 4, 1889 to March, 26, 1997; s2is stands for the sample from January, 5, 2000 to July, 5, 2006; s3is stands for the sample from January, 4, 1989 to December, 27, 2000; aos stands for the sample from October, 8, 2003 to September, 2, 2008; s1os stands for the sample from April, 2, 1997 to December, 29, 1999; s2os stands for the sample from July, 12, 2006 to September, 2, 2008; s3os stands for the sample from January, 3, 2001 to December, 30, 2004.

The sample periods for the pre-WWII data are defined by s1is, s2is for the in-sample results and by s1os, s2os for the out- of-sample results. More specifically, s1is stands for the sample from January, 31, 1885 to January, 9, 1909; s2os stands for the sample from January, 1 , 1921 to January, 23, 1932; s1os stands for the sample from January, 16, 1909 to December, 31, 1916; s2os stands for the sample from January, 30,1932 to October, 5, 1935.

$2 . * * * * *$ and ${ }^{*}$ stand for significance at the $1 \%, 5 \%$ and $10 \%$ level respectively. $n s$ stands for non-significance of the Giacomini and White statistic. 
Table 5: The ranking of CRRA hedging performance based on the Diebold and Mariano test statistic, comparison of the asymmetric basis model with the simple OLS-model and the

GARCH(1,1)-model. Daily, Weekly and Monthly horizon.

\begin{tabular}{|c|c|c|c|c|c|c|c|c|c|c|c|c|}
\hline & \multicolumn{8}{|c|}{ Contemporary data } & \multicolumn{4}{|c|}{ Pre-WWII data } \\
\hline & \multicolumn{4}{|c|}{ In-sample } & \multicolumn{4}{|c|}{ Out-of-sample } & \multicolumn{2}{|c|}{ In-sample } & \multicolumn{2}{|c|}{ Out-of-sample } \\
\hline & all & s1 & s2 & s3 & all & s1 & $\mathrm{s} 2$ & s3 & s1 & s2 & s1 & $\mathrm{s} 2$ \\
\hline \multicolumn{13}{|c|}{ 1. Daily hedging horizon } \\
\hline \multicolumn{13}{|c|}{ Panel A: Corn } \\
\hline basis & 3 & 2 & 3 & 3 & 3 & 1 & 3 & 2 & 3 & 1 & 3 & 2 \\
\hline garch & 1 & 1 & 1 & 1 & 2 & 2 & 2 & 1 & 2 & 2 & 2 & 3 \\
\hline ols & 2 & 3 & 2 & 2 & 1 & 3 & 1 & 3 & 1 & 3 & 1 & 1 \\
\hline \multicolumn{13}{|c|}{ Panel B: Wheat } \\
\hline basis & 1 & 2 & 1 & 1 & 2 & 1 & 1 & 2 & 2 & 2 & 2 & 2 \\
\hline garch & 3 & 1 & 3 & 2 & 3 & 2 & 3 & 3 & 3 & 3 & 1 & 1 \\
\hline ols & 2 & 3 & 2 & 3 & 1 & 3 & 2 & 1 & 1 & 1 & 3 & 3 \\
\hline \multicolumn{13}{|c|}{ Panel C: Soybeans } \\
\hline basis & 3 & 2 & 2 & 1 & 2 & 2 & 3 & 2 & - & - & - & - \\
\hline garch & 2 & 1 & 3 & 2 & 3 & 1 & 2 & 3 & - & - & - & - \\
\hline ols & 1 & 3 & 1 & 3 & 1 & 3 & 1 & 1 & - & - & - & - \\
\hline \multicolumn{13}{|c|}{ 2. Weekly hedging horizon } \\
\hline \multicolumn{13}{|c|}{ Panel A: Corn } \\
\hline basis & 2 & 1 & 3 & 2 & 3 & 3 & 3 & 2 & 3 & 2 & 3 & 2 \\
\hline garch & 3 & 2 & 2 & 1 & 2 & 2 & 2 & 1 & 2 & 3 & 2 & 3 \\
\hline ols & 1 & 3 & 1 & 3 & 1 & 1 & 1 & 3 & 1 & 1 & 1 & 1 \\
\hline \multicolumn{13}{|c|}{ Panel B: Wheat } \\
\hline basis & 1 & 3 & 1 & 1 & 1 & 1 & 1 & 1 & 2 & 3 & 2 & 3 \\
\hline garch & 3 & 2 & 3 & 3 & 3 & 2 & 3 & 2 & 1 & 2 & 3 & 2 \\
\hline ols & 2 & 1 & 2 & 2 & 2 & 3 & 2 & 3 & 3 & 1 & 1 & 1 \\
\hline \multicolumn{13}{|c|}{ Panel C: Soybeans } \\
\hline basis & 3 & 2 & 3 & 2 & 3 & 3 & 3 & 2 & - & - & - & - \\
\hline garch & 2 & 1 & 1 & 1 & 2 & 1 & 2 & 3 & - & - & - & - \\
\hline ols & 1 & 3 & 2 & 3 & 1 & 2 & 1 & 1 & - & - & - & - \\
\hline \multicolumn{13}{|c|}{ 3. Monthly hedging horizon } \\
\hline \multicolumn{13}{|c|}{ Panel A: Corn } \\
\hline basis & 2 & 1 & 1 & 2 & 1 & 3 & 3 & 2 & - & - & - & - \\
\hline garch & 3 & 3 & 2 & 3 & 3 & 1 & 1 & 1 & - & - & - & - \\
\hline & 1 & 2 & 3 & 1 & 2 & 2 & 2 & 3 & - & - & - & - \\
\hline \multicolumn{13}{|c|}{ Panel B: Wheat } \\
\hline basis & 1 & 3 & 1 & 1 & 1 & 2 & 2 & 1 & - & - & - & - \\
\hline garch & 2 & 1 & 2 & 3 & 2 & 3 & 1 & 2 & - & - & - & - \\
\hline ols & 3 & 2 & 3 & 2 & 3 & 1 & 3 & 3 & - & - & - & - \\
\hline \multicolumn{13}{|c|}{ Panel C: Soybeans } \\
\hline basis & 3 & 1 & 2 & 2 & 1 & 3 & 1 & 1 & - & - & - & - \\
\hline garch & 2 & 2 & 3 & 1 & 3 & 1 & 3 & 2 & - & - & - & - \\
\hline ols & 1 & 3 & 1 & 3 & 2 & 2 & 2 & 3 & - & - & - & - \\
\hline
\end{tabular}

Notes: 1 . The sample periods for the contemporary data are defined by ais, s1is, s2is, s3is for the in-sample results and by aos, s1os, s2os and s3os for the out-of-sample results. More specifically, ais stands for the sample from January, 4, 1989 to October, 1,$2003 ;$ s1is stands for the sample from January, 4, 1889 to March, 26, 1997; s2is stands for the sample from January, 5, 2000 to July, 5, 2006; s3is stands for the sample for the sample from April, 2, 1997 to December, 29, 1999; s2os stands for the sample from July, 12, 2006 to September, 2, 2008; s3os stands for the sample from January, 3, 2001 to December, 30, 2004.

The sample periods for the pre-WWII data are defined by s1is, s2is for the in-sample results and by s1os, s2os for the out- of-sample results. More specifically, s1is stands for the sample from January, 31, 1885 to January, 9, 1909; s2os stands for the sample from January, 1 , 1921 to January, 23, 1932; s1os stands for the sample from January, 16, 1909 to December, 31, 1916; s2os stands for the sample from January, 30, 1932 to October, 5, 1935 .

2. The performance is ranked according to the number of times one model beats all other models. 
Figure 3: The negative convenience yield for corn, wheat and soybeans; contemporary data, daily frequency.

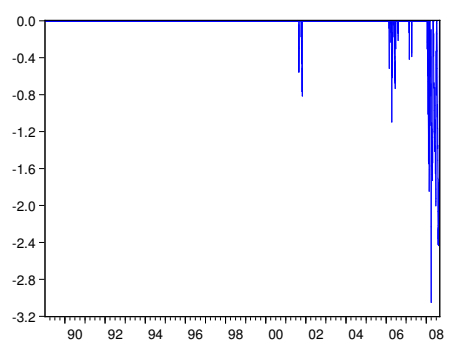

(a) Corn

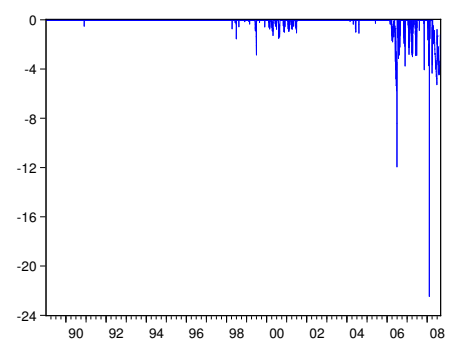

(b) Wheat

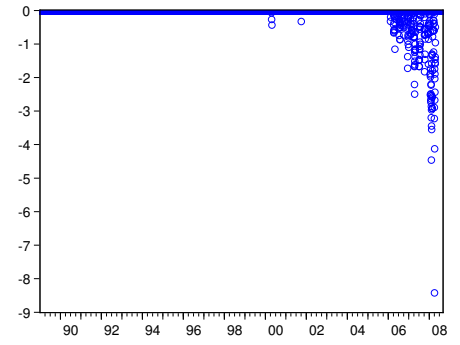

(c) Soybeans

respectively. Table 9 shows the results for the pre-WWII daily and weekly data. The results show little evidence of abundance increasing spot and futures price volatilities for storable agricultural commodity markets.

For the recent corn, wheat and soybeans data at the daily frequency, we find some asymmetry in the effect of the basis - albeit not in the sense that both positive and negative basis increase the volatility. For corn and soybeans, the information criteria lead us to choose the asymmetric model in all but one sample. Moreover, the coefficients of both the positive and the negative basis are highly significant. For wheat, the results are somewhat different. The positive basis is the significant variable, the negative basis is not. This in itself is also a form of asymmetry since the symmetric basis is outperformed by the asymmetric positive basis according to the information criteria. The main result, however, is that only the positive basis variable leads to an increase in spot and futures return volatility. The coefficient for the negative basis, if significant, is positive and small, indicating that abundance, as measured by a negative basis, leads to a small decrease in volatility and not an increase as documented by Lien and Yang (2008) and Kogan et al (2008).

Still at the daily frequency, the convenience yield seems to have a strong asymmetric effect on spot and futures return volatility. A negative convenience yield even leads to a stronger increase in volatility than a positive convenience yield. However, these results have to be interpreted with care. Figure 3 shows that the convenience yield for corn, wheat and soybeans only turns negative for a short period between 2000 and 2001, and after 2005. Those periods 
are characterized by a poor convergence performance of CBOT corn, wheat and soybeans futures contracts as documented by Irwin, Garcia, Good and Kunda (2009). Given that poor convergence periods are characterized by higher volatilities, the asymmetric effects of the convenience yield are likely to be driven more by the convergence problems than by the impact of abundance.

The results for the recent corn, wheat and soybeans data at the weekly frequency also point towards the existence of some asymmetric effects, mainly for the basis, the cy and the spot model. Again, a positive basis leads to higher spot and futures volatilities while a negative basis decreases volatilities. We also find that the coefficient of the negative basis is smaller than that of the positive basis. For the convenience yield, we refer to the above paragraph for the interpretation of the coefficients. The results for the spot model show that both a positive deviation and a negative deviation of the spot price from its short-term trend leads to an increase in spot and futures return volatility, at least for a number of sample periods for wheat and soybeans. Finally, the results indicate that a negative deviation from the long-term trend in inventory levels - both weekly inventories regular for deliveries as quarterly on- and off-farm inventories in Illinois and Ohio - increases spot and futures return significantly. ${ }^{16}$ Note in this respect that the coefficients for both the weekly inventories regular for deliveries and the quarterly on- and off-farm inventories are significant for all sub-samples. Thus, at first sight, the changes in delivery system that occurred in 2000 do not seem to have influenced commodity price reactions to published inventory levels.

The results for the recent corn, wheat and soybeans data at the monthly frequency are similar, but often less or non significant. This may be an indication that spot and futures need less than a month to react to changes in scarcity variables. It may also mean a smaller sample and lower power.

For the pre-WWII data, the results are less clear. There seems to have been a V-shaped relationship between the asymmetric basis and the volatility of commodity spot returns for wheat and corn. However, this relationship is not present for commodity futures returns. As far as the convenience yield is concerned, we find again that the convenience yield seems to have a strong asymmetric effect on spot and futures return volatility. However, as for the recent

\footnotetext{
${ }^{16}$ There are a few exceptions for the recent weekly wheat data.
} 
data, this asymmetric effect is driven by a small number of observations. For the weekly data between 1885 and 1916, the convenience yield is negative only 18 times out of 1666 . Deviations of the spot price from its short-term trend and deviations of the inventory level from its trend only have a significant impact on spot and futures prices volatilities before the first World War. 


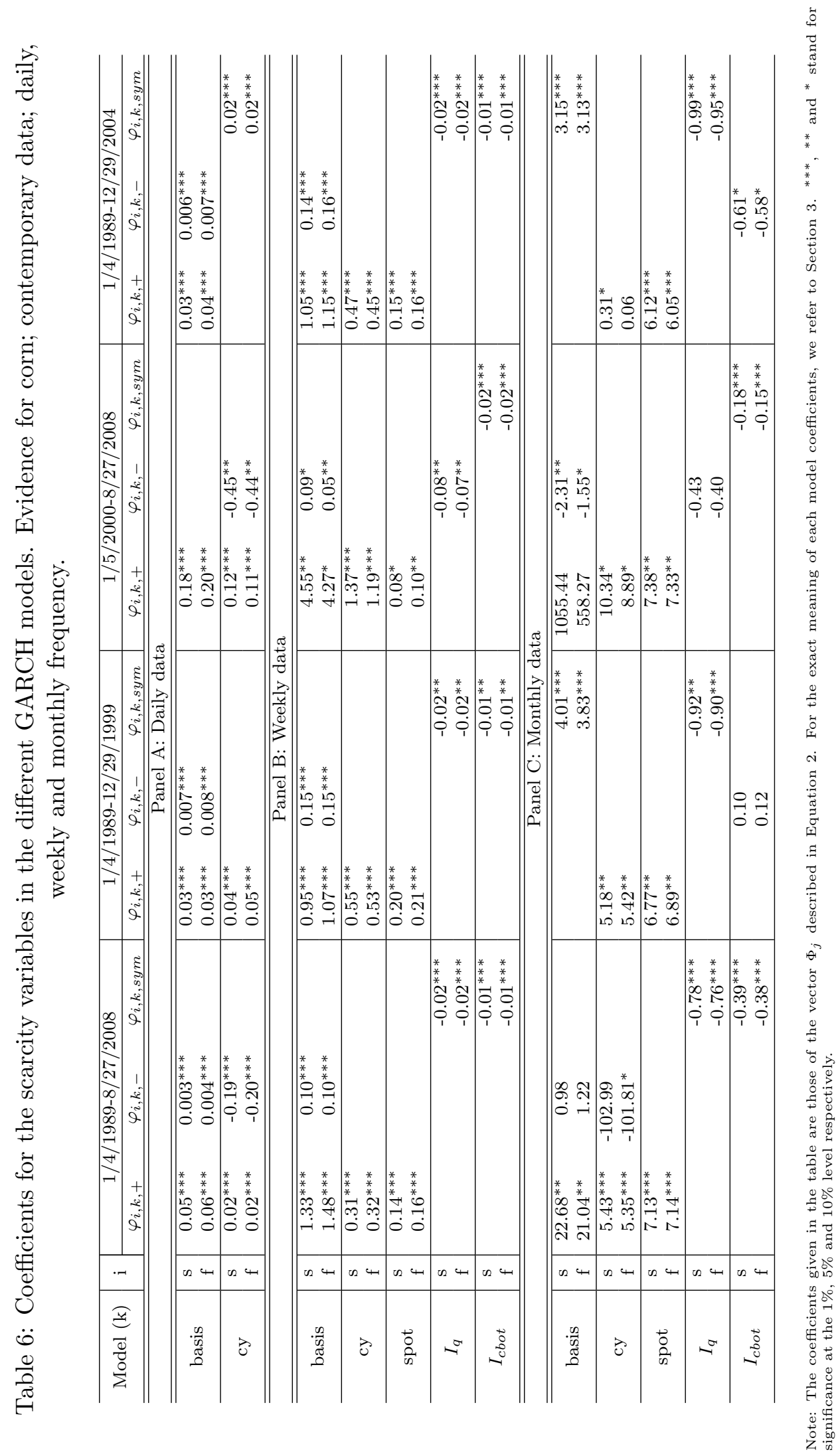




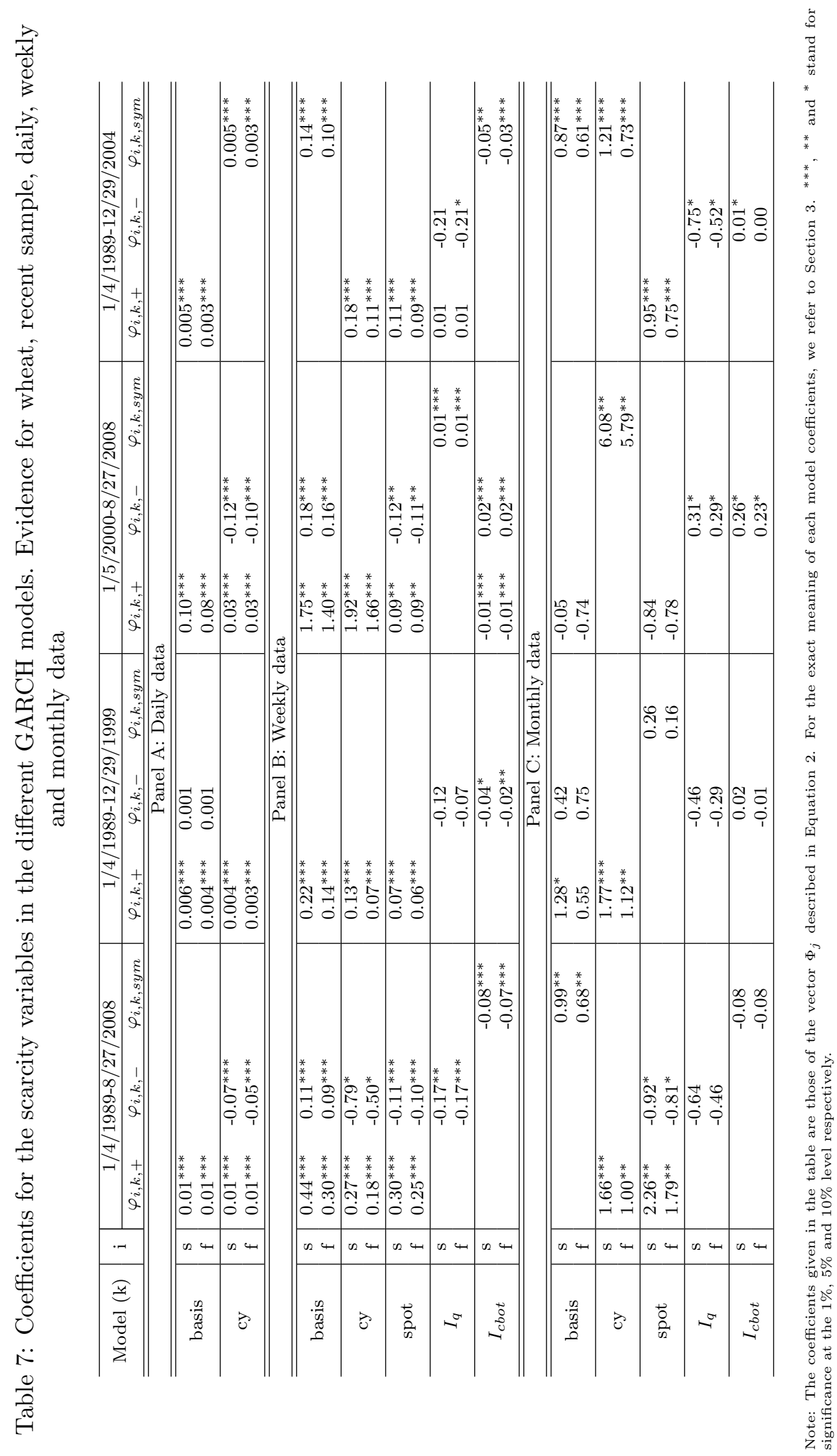




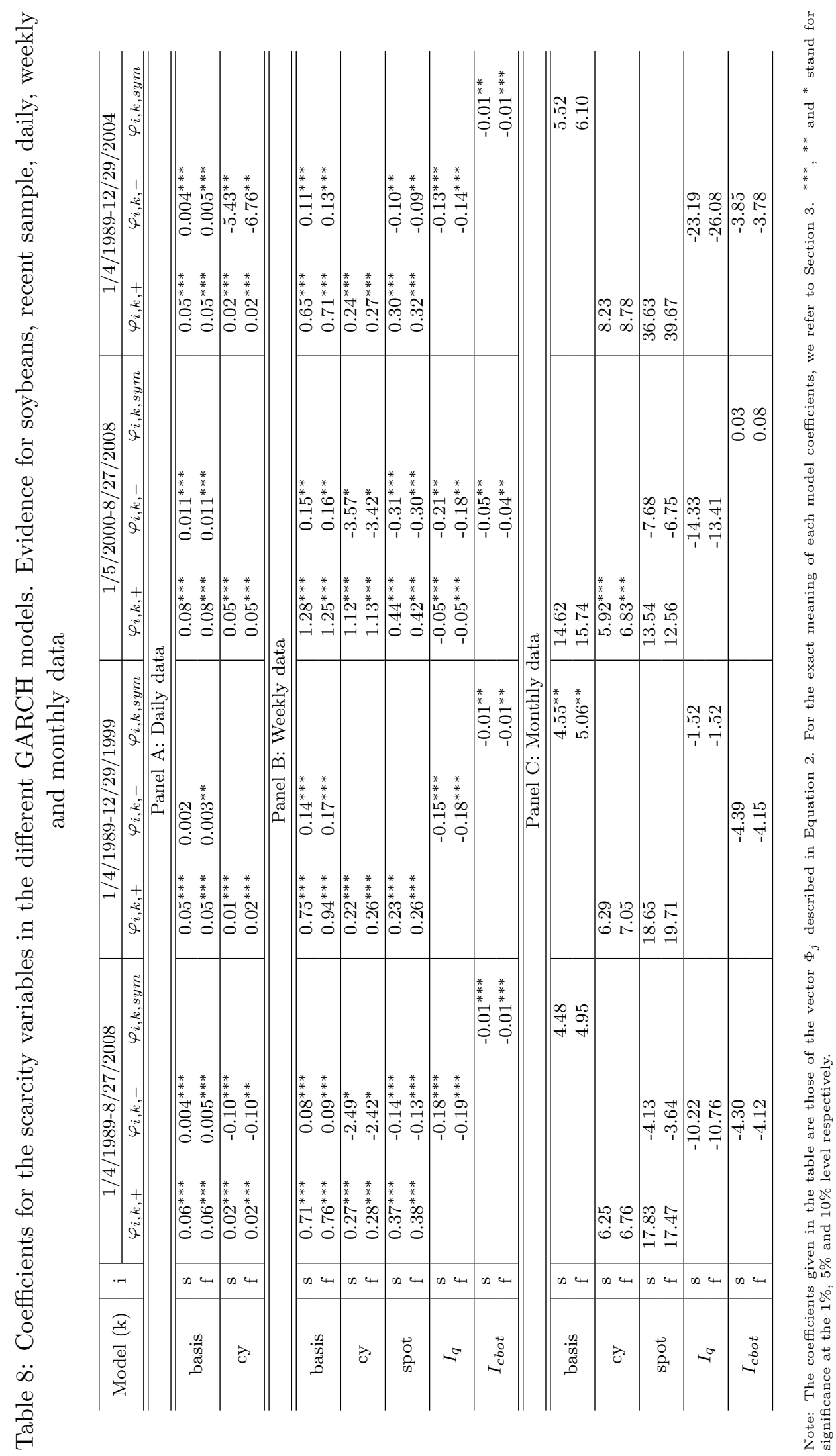




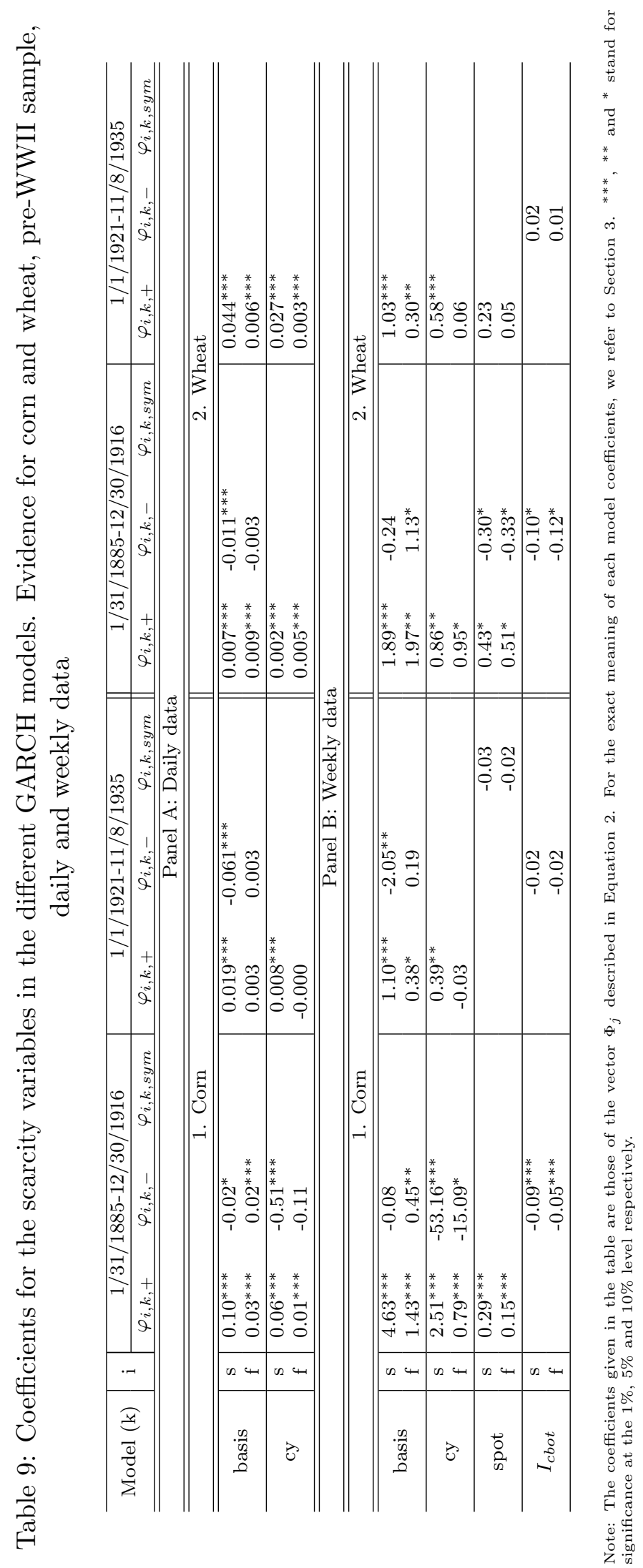




\subsection{The impact of different scarcity measures on hedging performance}

To finalize the discussion of the empirical results, we turn to the impact of different scarcity measures on hedging performance. Table 10 shows which model outperforms all others in terms of minimum-variance hedging performance according to the Diebold and Mariano test statistic. Table 11 ranks the models for the CRRA utility function. Tables 20, 21 and 22 in appendix give the full results.

The main result that emerges from the tables is that the basis model does not at all consis-

tently outperform all others, certainly for weekly and monthly data. Other scarcity/abundance models perform better for some sample periods and hedging horizons. Unfortunately, not one model stands out across commodities, sub-samples and hedging horizons for the contemporary data. It seems that the best model is highly dependent on circumstances prevailing at different times.

An interesting sidenote concerns the strong and robust performance of the OLS and the GARCH model for the pre-WWII data. From the data, it appears that futures markets have evolved significantly over time. In the past, investors could count on OLS to lead to the best hedging performance, but these days, more complicated models are in order.

The final question that has to be answered is whether investors should invest in finding out which model is likely to perform better in a certain period. To get an indication, we give the following numbers: for out-of-sample minimum-variance weekly corn results, using the best model leads to a potential decrease in portfolio variance of $2.9 \%$ to $22.1 \%$ on average for the total sample, $1.9 \%$ to $15.5 \%$ for the first sample, $5.1 \%$ to $68.3 \%$ for the second sample and $2.0 \%$ to $7.0 \%$ for the third sample. Thus, there is a strong improvement in overall out-of-sample portfolio variance if an investor uses the best model as opposed to the worst model. But even models that are close-by in terms of ranking can lead to substantial variance reductions.

\section{Conclusion}

In this paper, we analyzed whether scarcity and abundance have an asymmetric effect on the volatility and covariance of spot and futures prices, and whether including this effect in the computation of the hedge ratio improves hedging performance. More specifically, we first tested 
Table 10: Best performing model in terms of minimum variance hedging performance based on the Diebold and Mariano test statistic. Daily, weekly and monthly horizon.

\begin{tabular}{|c|c|c|c|c|c|c|c|c|c|c|c|c|}
\hline & \multicolumn{8}{|c|}{ Contemporary data } & \multicolumn{4}{|c|}{ Pre-WWII data } \\
\hline & \multicolumn{4}{|c|}{ In-sample } & \multicolumn{4}{|c|}{ Out-of-sample } & \multicolumn{2}{|c|}{ In-sample } & \multicolumn{2}{|c|}{ Out-of-sample } \\
\hline & all & s1 & s2 & s3 & all & s1 & s2 & s3 & s1 & s2 & s1 & $\mathrm{s} 2$ \\
\hline \multicolumn{13}{|c|}{ Panel A: Corn } \\
\hline daily & basis & ols & ols & basis & basis & $c y$ & basis & basis & ols & ols & ols & ols \\
\hline weekly & all & basis & all & basis & spot & $c y$ & all & $c y$ & ols & ols & ols & ols \\
\hline monthly & basis & $I_{c b o t}$ & garch & $c y$ & $I_{c b o t}$ & ols & $I_{q}$ & garch & & & & \\
\hline \multicolumn{13}{|c|}{ Panel B: Wheat } \\
\hline daily & ols & ols & ols & ols & garch & garch & ols & basis & ols & ols & ols & ols \\
\hline weekly & ols & $I_{q}$ & all & ols & basis & garch & $I_{q}$ & basis & ols & ols & ols & ols \\
\hline monthly & spot & spot & garch & $I_{\text {cbot }}$ & ols & $I_{c b o t}$ & $I_{q}$ & $c y$ & & & & \\
\hline \multicolumn{13}{|c|}{ Panel C: Soybeans } \\
\hline daily & ols & ols & $c y$ & ols & basis & ols & $c y$ & ols & - & - & - & - \\
\hline weekly & all & $I_{\text {cbot }}$ & ols & all & ols & $c y$ & $c y$ & ols & - & - & - & - \\
\hline monthly & basis & garch & cy & basis & basis & $I_{c b o t}$ & garch & basis & - & - & - & - \\
\hline
\end{tabular}

Notes: 1. The sample periods for the contemporary data are defined by ais, s1is, s2is, s3is for the in-sample results and by aos, s1os, s2os and s3os for the out-of-sample results. More specifically, ais stands for the sample from January, 4, 1989 to October, 1, 2003; s1is stands for the sample from January, 4, 1889 to March, 26, 1997; s2is stands for the sample from January, 5, 2000 to July, 5, 2006; s3is stands for the sample from January, 4, 1989 to December, 27, 2000; aos stands for the sample from October, 8, 2003 to September, 2, 2008; s1os stands for the sample from April, 2, 1997 to December, 29, 1999; s2os stands for the sample from July, 12, 2006 to September, 2, 2008; s3os stands for the sample from January, 3, 2001 to December, 30, 2004.

The sample periods for the pre-WWII data are defined by s1is, s2is for the in-sample results and by s1os, s2os for the out- of-sample results. More specifically, s1is stands for the sample from January, 31, 1885 to January, 9, 1909; s2os stands for the sample from January, 1, 1921 to January, 23, 1932; s1os stands for the sample from January, 16, 1909 to December, 31, 1916; s2os stands for the sample from January, 30,1932 to October, 5, 1935.

2. The performance is ranked according to the number of times one model beats all other models.

Table 11: Best performing model in terms of CRRA hedging performance based on the Diebold and Mariano test statistic. Daily, weekly and monthly horizon.

\begin{tabular}{|c|c|c|c|c|c|c|c|c|c|c|c|c|}
\hline & \multicolumn{8}{|c|}{ Contemporary data } & \multicolumn{4}{|c|}{ Pre-WWII data } \\
\hline & \multicolumn{4}{|c|}{ In-sample } & \multicolumn{4}{|c|}{ Out-of-sample } & \multicolumn{2}{|c|}{ In-sample } & \multicolumn{2}{|c|}{ Out-of-sample } \\
\hline & all & s1 & s2 & s3 & all & s1 & s2 & s3 & s1 & $\mathrm{s} 2$ & s1 & s2 \\
\hline \multicolumn{13}{|c|}{ Panel A: Corn } \\
\hline daily & garch & garch & $c y$ & garch & ols & $c y$ & ols & $c y$ & ols & basis & ols & ols \\
\hline weekly & ols & $c y$ & ols & spot & ols & $I_{q}$ & ols & $I_{c b o t}$ & ols & ols & ols & ols \\
\hline monthly & $c y$ & basis & basis & $c y$ & basis & $c y$ & garch & garch & & & & \\
\hline \multicolumn{13}{|c|}{ Panel B: Wheat } \\
\hline daily & basis & garch & basis & $c y$ & ols & basis & basis & ols & ols & ols & garch & garch \\
\hline weekly & spot & spot & all & spot & spot & all & spot & basis & garch & ols & ols & ols \\
\hline monthly & spot & spot & basis & basis & basis & ols & garch & spot & & & & \\
\hline \multicolumn{13}{|c|}{ Panel C: Soybeans } \\
\hline daily & ols & garch & ols & basis & ols & garch & ols & basis & - & - & - & - \\
\hline weekly & ols & $I_{q}$ & garch & $I_{q}$ & ols & $I_{\text {cbot }}$ & ols & ols & - & - & - & - \\
\hline monthly & all & $I_{q}$ & $c y$ & all & all & $I_{\text {cbot }}$ & basis & all & - & - & - & - \\
\hline
\end{tabular}

Notes: 1. The sample periods for the contemporary data are defined by ais, s1is, s2is, s3is for the in-sample results and by aos, s1os, s2os and $\mathrm{s} 3 \mathrm{os}$ for the out-of-sample results. More specifically, ais stands for the sample from January, 4, 1989 to October, 1, 2003; s1is stands for the sample from January, 4, 1889 to March, 26, 1997; s2is stands for the sample from January, 5, 2000 to July, 5, 2006; s3is stands for the sample from January, 4, 1989 to December, 27, 2000; aos stands for the sample from October, 8, 2003 to September, 2, 2008; s1os stands for the sample from April, 2, 1997 to December, 29, 1999; s2os stands for the sample from July, 12, 2006 to September, 2, 2008; s3os stands for the sample from January, 3, 2001 to December, 30, 2004.

The sample periods for the pre-WWII data are defined by s1is, s2is for the in-sample results and by s1os, s2os for the out- of-sample results. More specifically, s1is stands for the sample from January, 31, 1885 to January, 9, 1909; s2os stands for the sample from January, 1 , 1921 to January, 23, 1932; s1os stands for the sample from January, 16, 1909 to December, 31, 1916; s2os stands for the sample from January, 30,1932 to October, 5,1935

2. The performance is ranked according to the number of times one model beats all other models. 
the presence and the robustness of the asymmetric effect documented by Lien and Yang (2008) for storable agricultural commodities by analyzing different sample periods, longer horizons and alternative utility functions. Overall, we can not confirm that the asymmetric effect is robust. We find evidence in favor of the asymmetric basis model of Lien and Yang (2008) for corn at the daily frequency, but not for wheat or soybeans, and not for lower frequencies. Second, we looked at the sign and the significance of the scarcity variable coefficients for each subsample and each data frequency. The results show that, as expected, scarcity increases spot and futures return volatility. However, there is little evidence of abundance having a similar effect. Finally, we analyzed whether including other scarcity variables increases hedging performance. Unfortunately, though using a more complicated model seems to improve hedging performance in many cases, not one model stands out across commodities, sub-samples and hedging performance. Moreover, in- and out-of-sample results often do not correspond so that it is very hard to find the best model out-of-sample. 
Appendix 


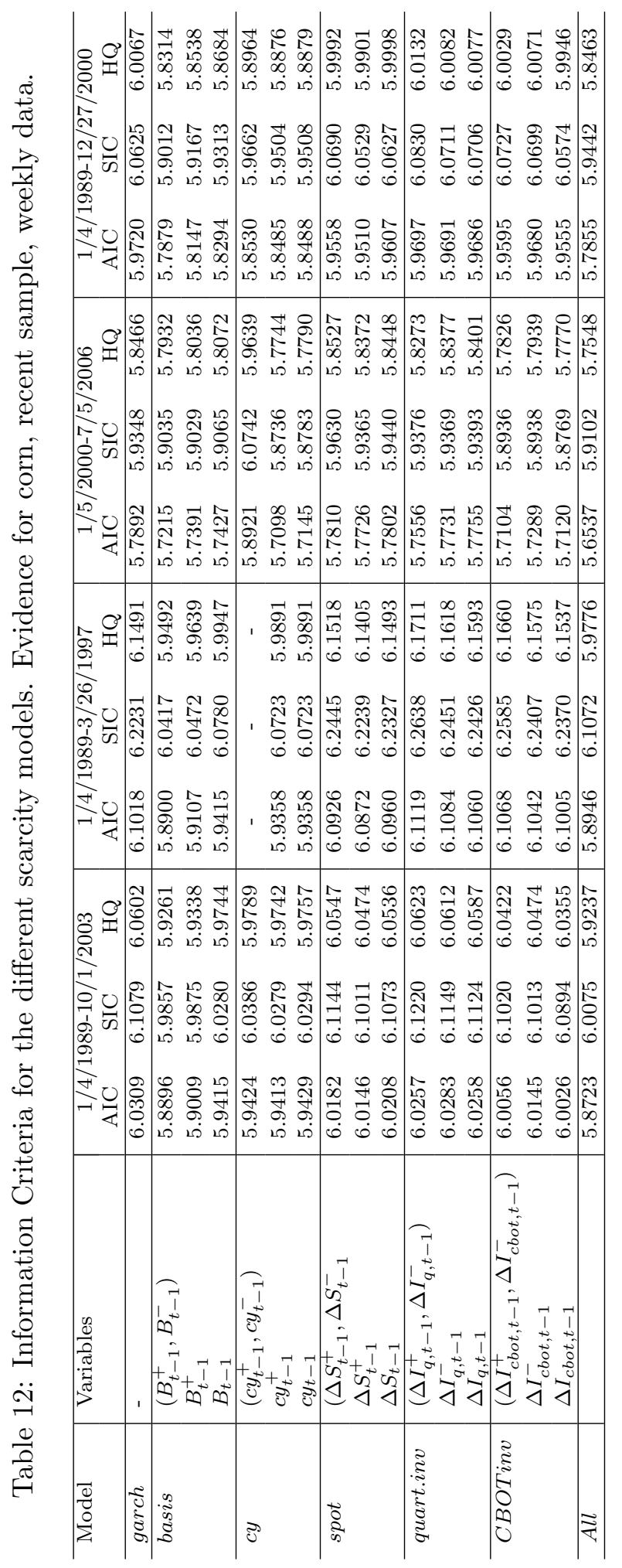




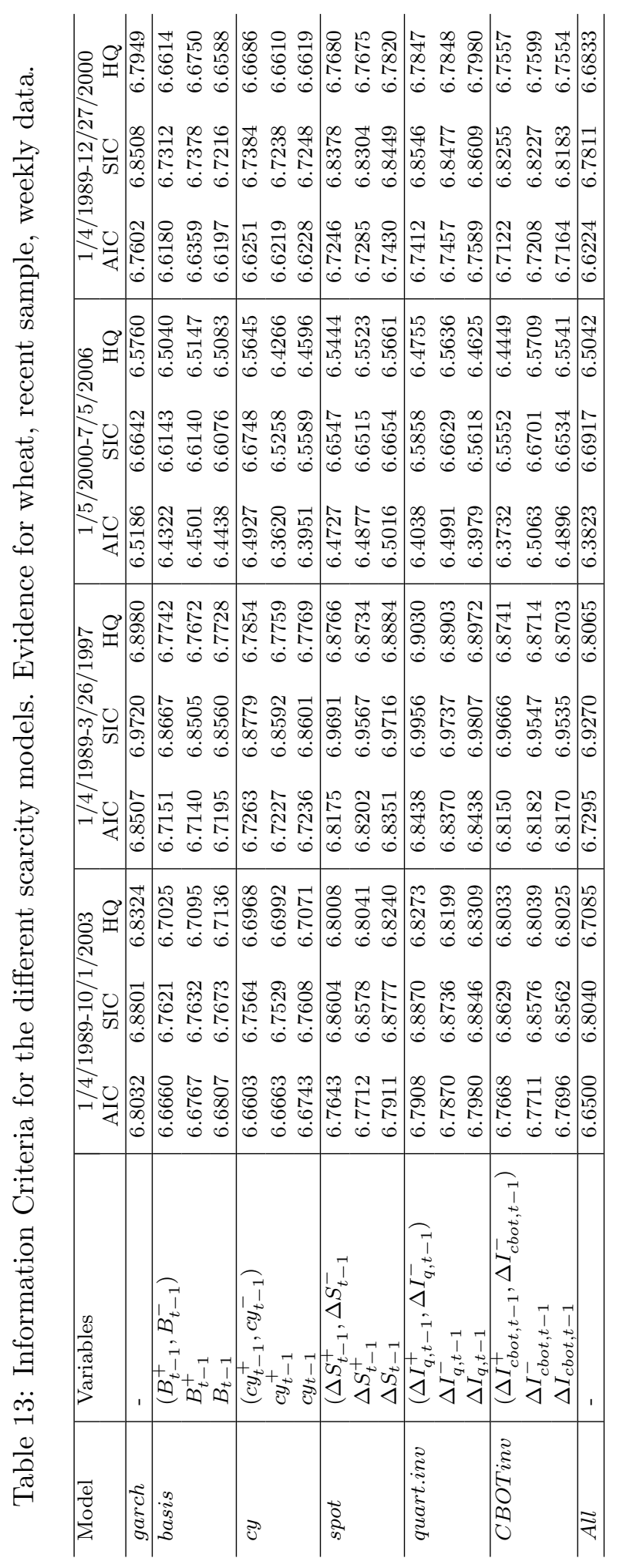




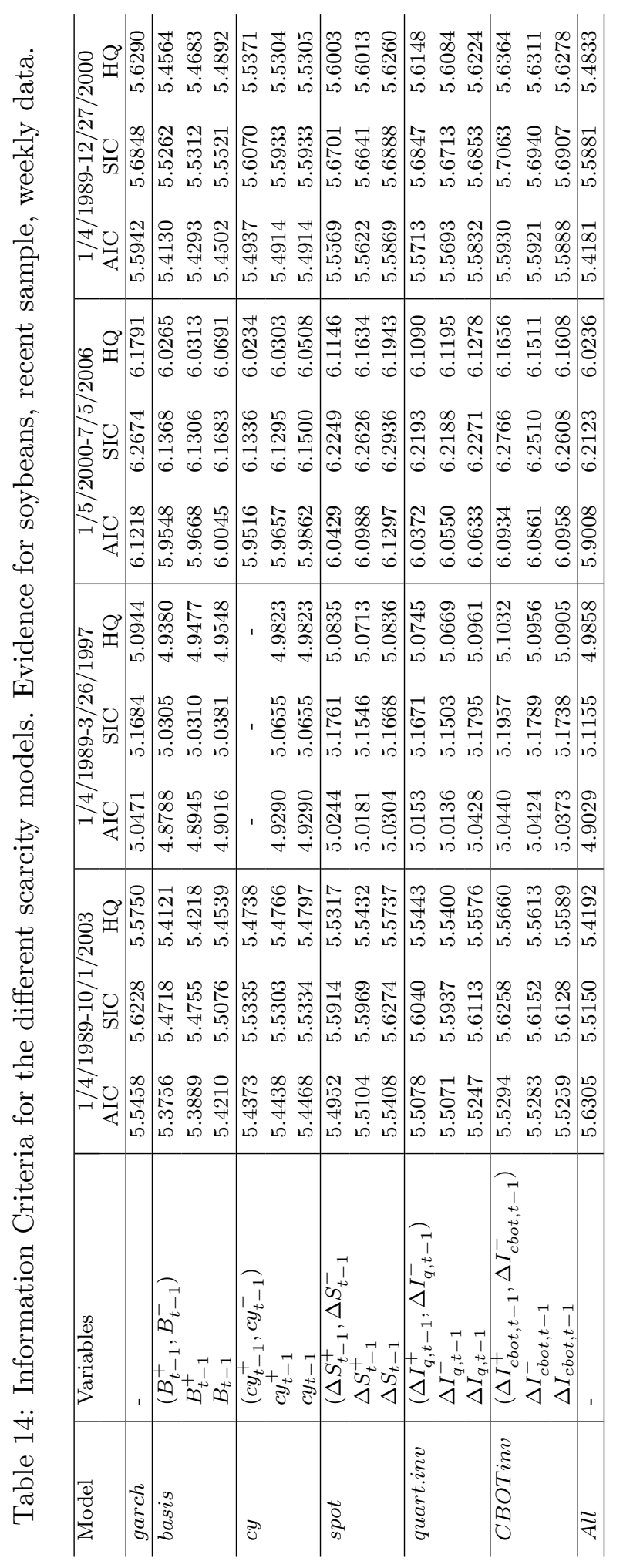




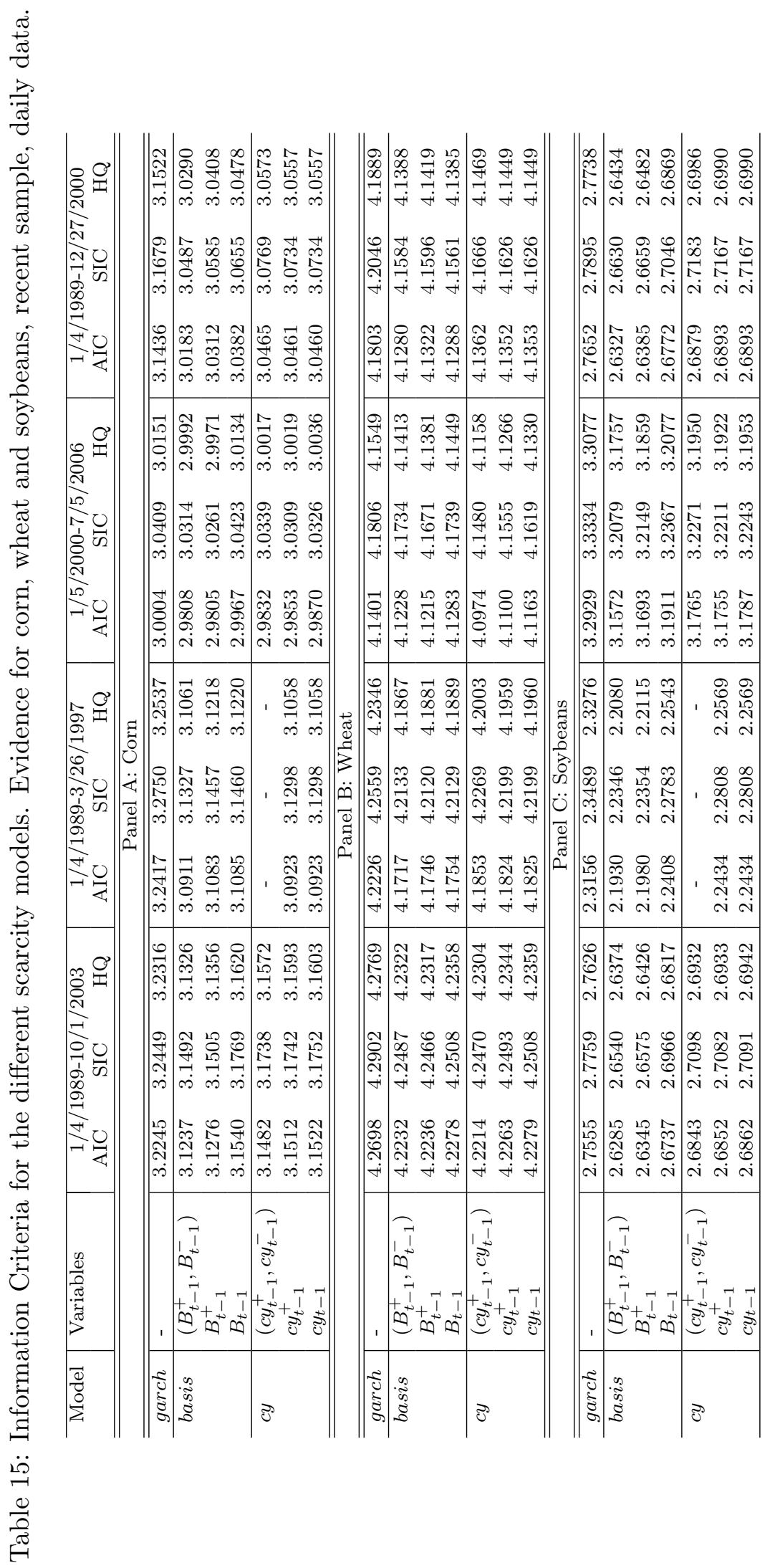




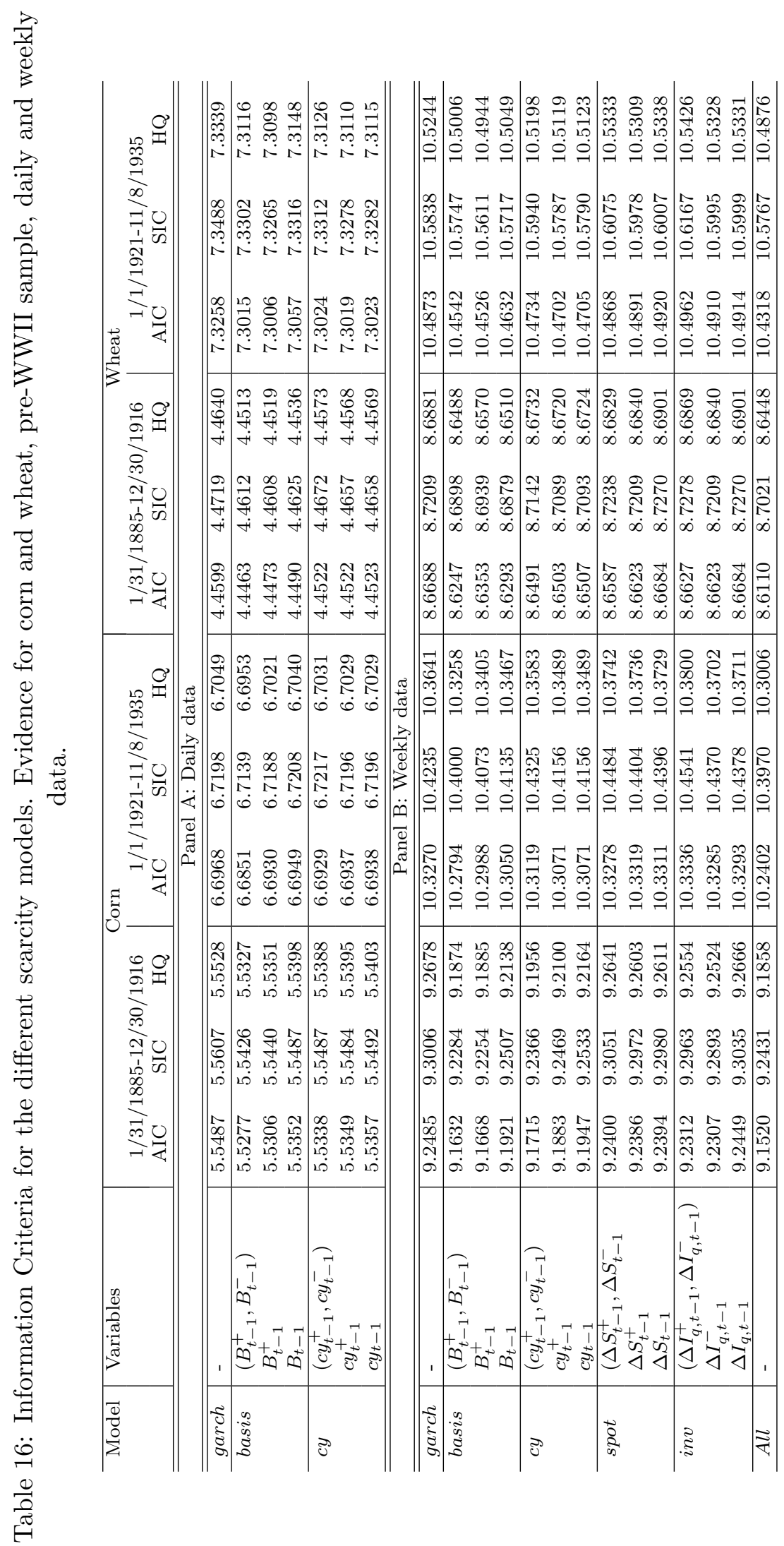




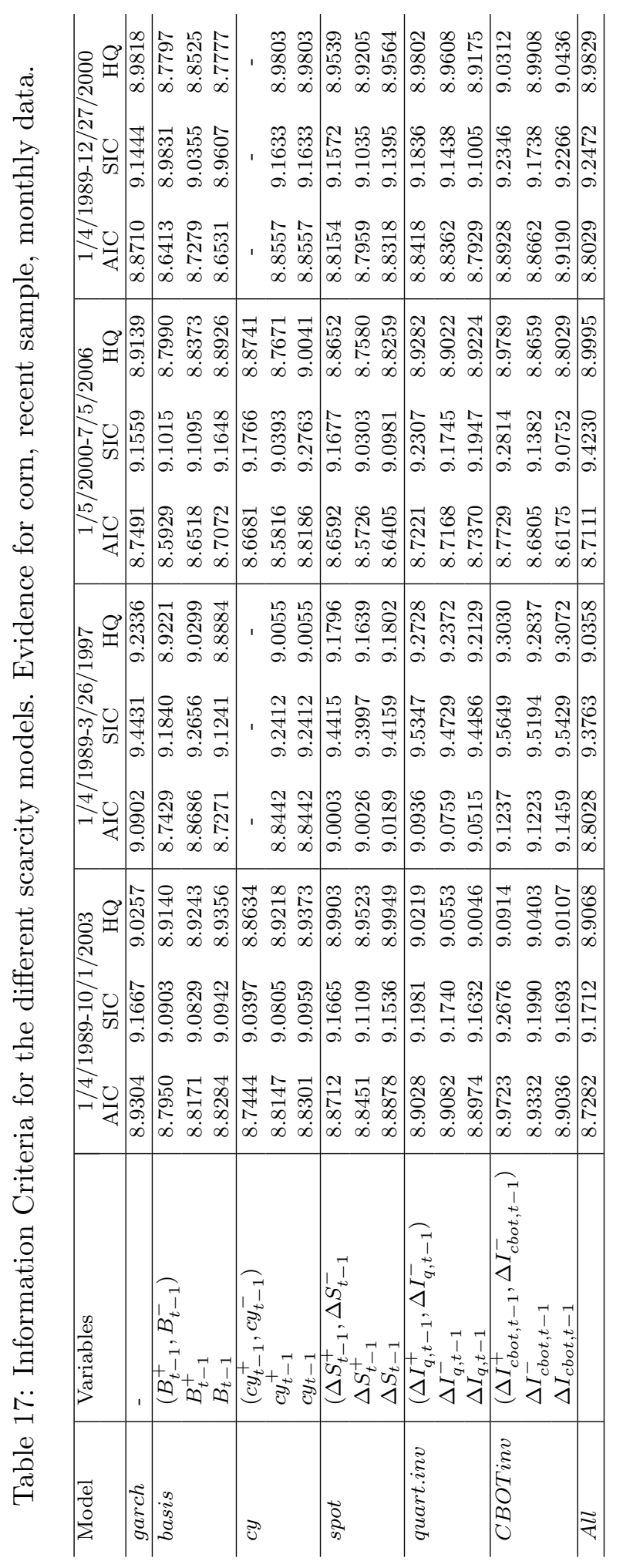




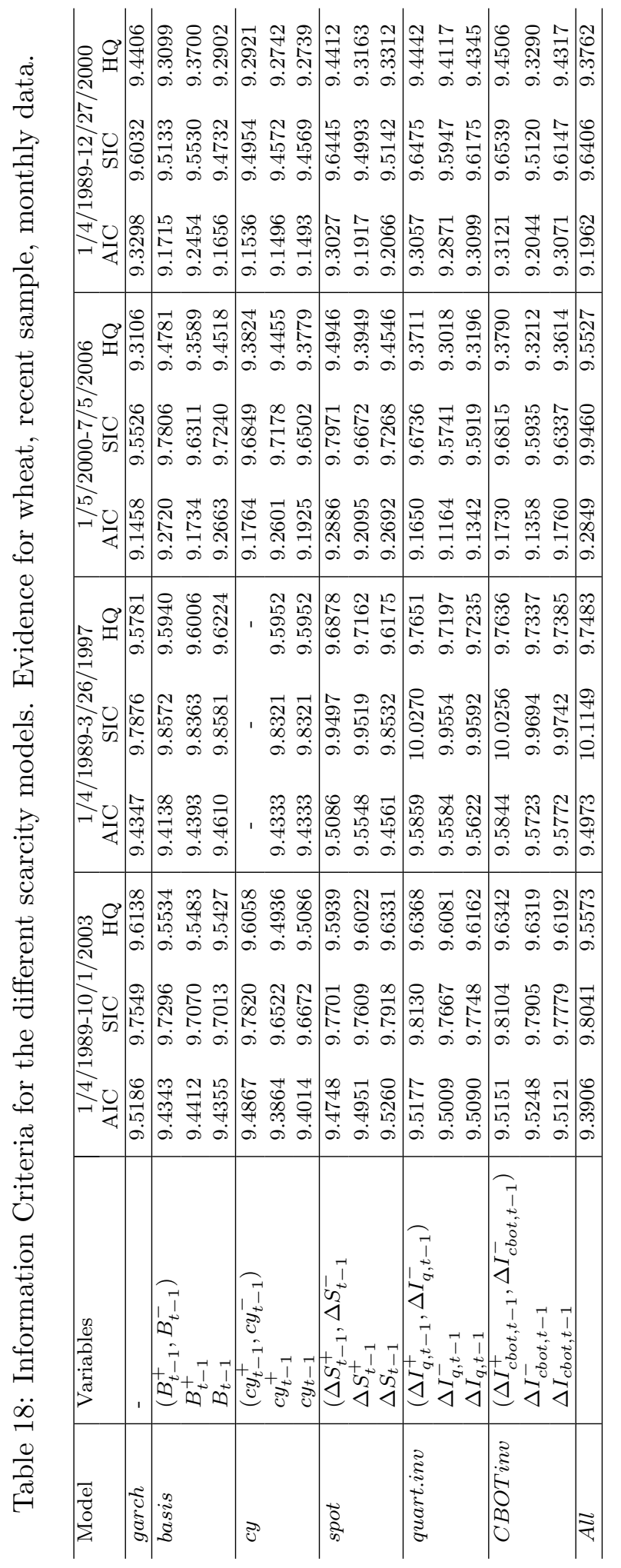




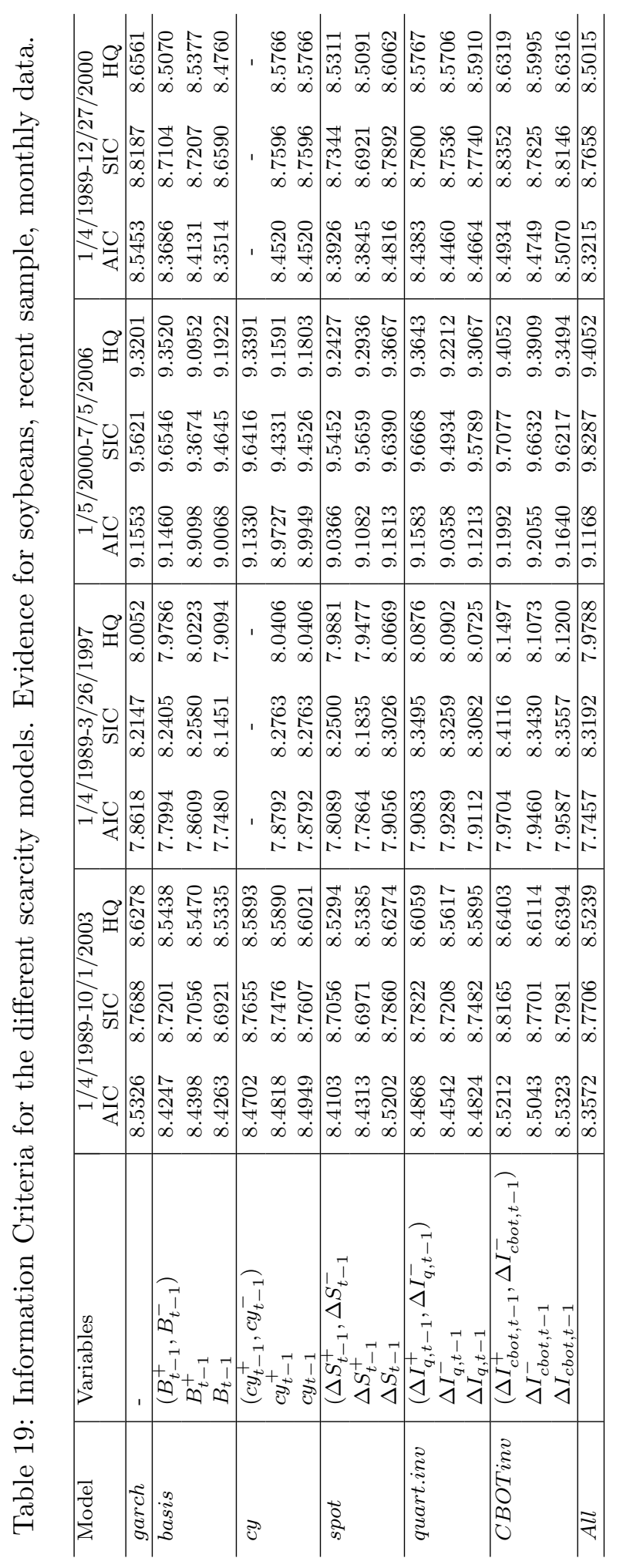




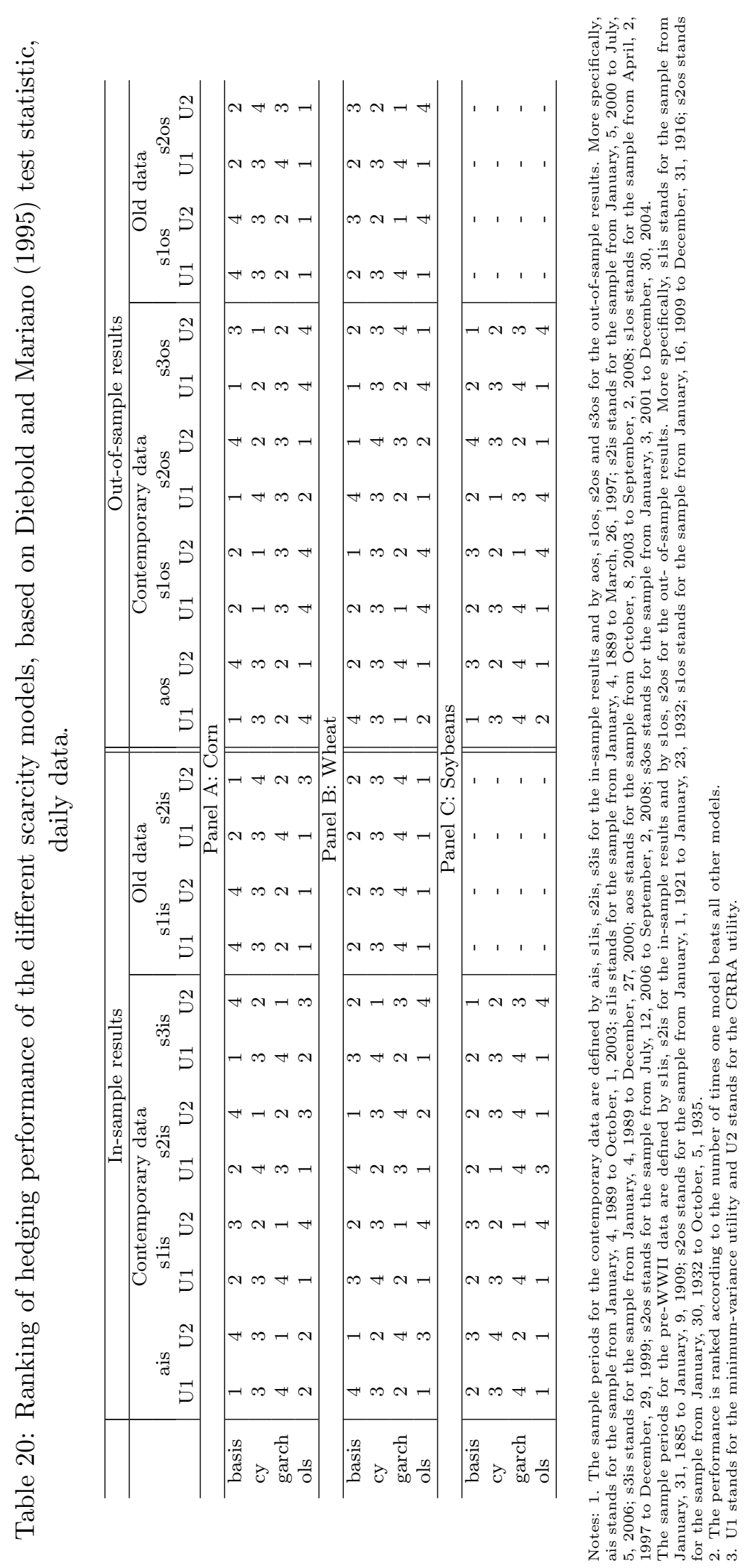




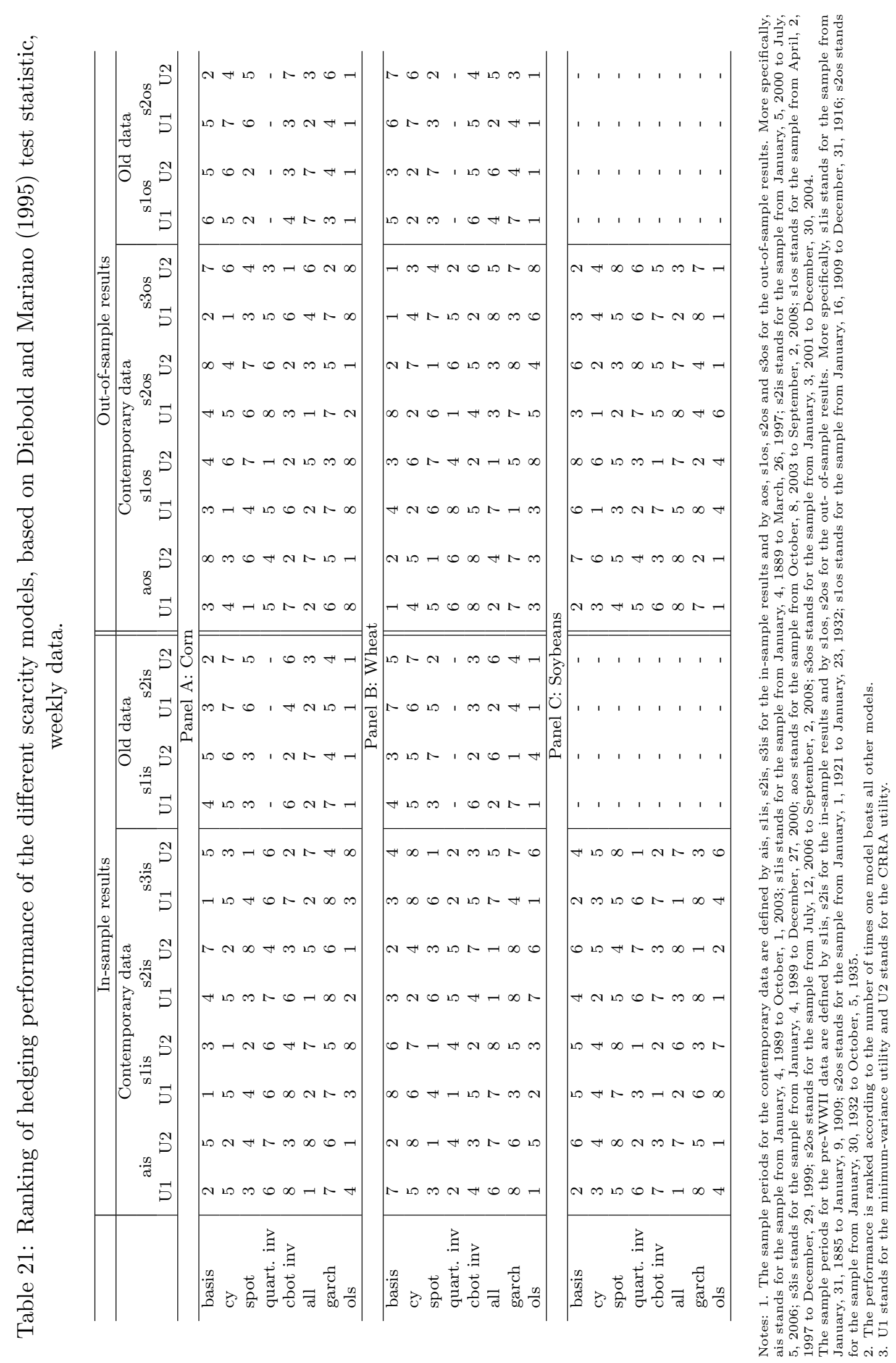




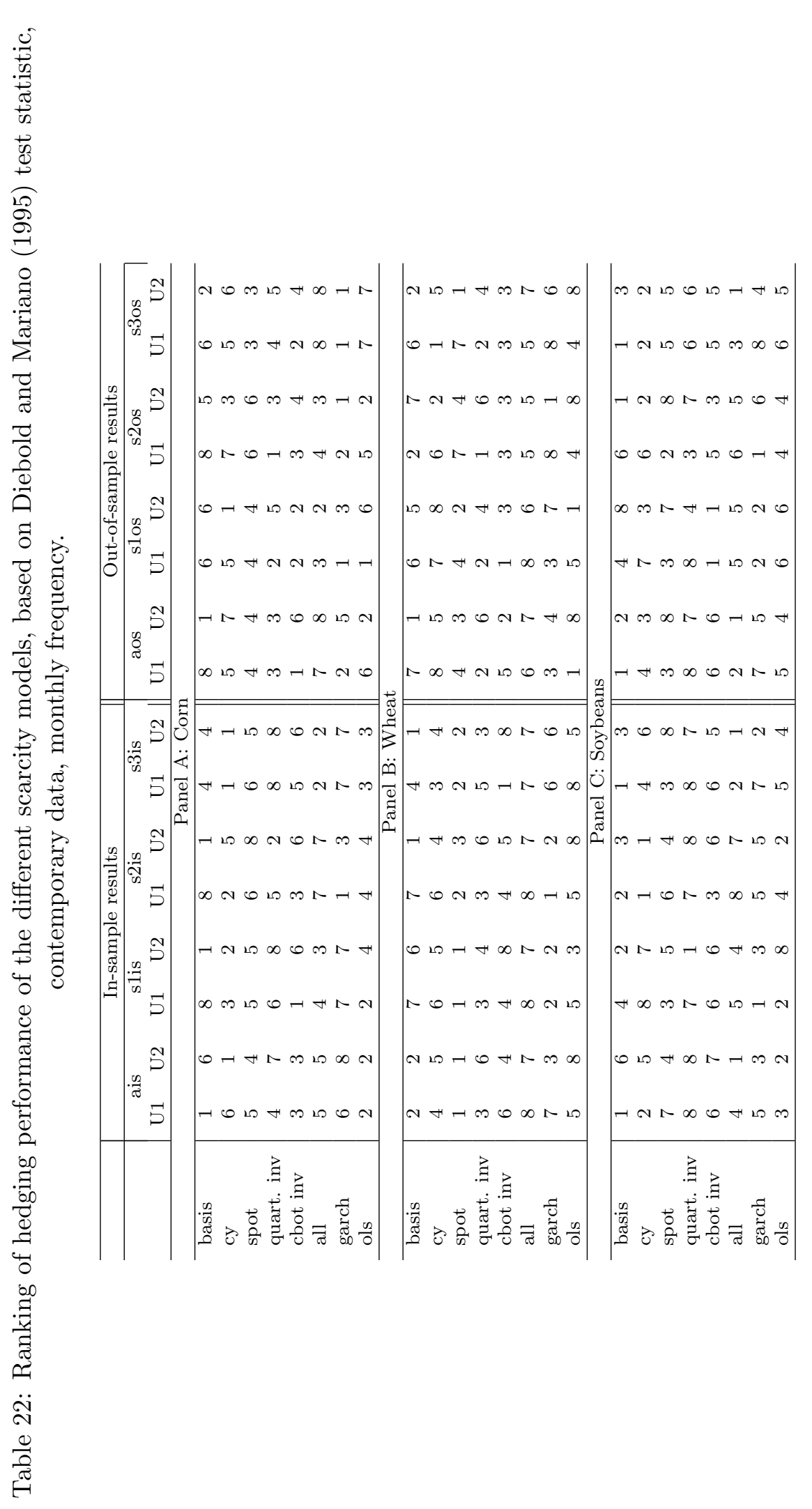

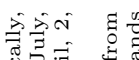

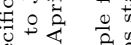

究各

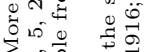

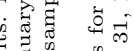

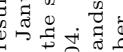

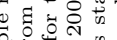

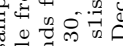

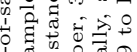

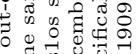

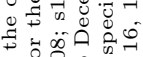

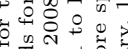

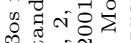

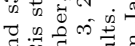

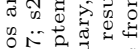

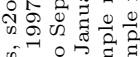

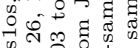

ư

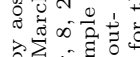

万人.

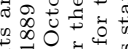

牙 + द

年

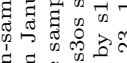

A

急

을 의

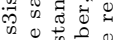

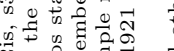

तु

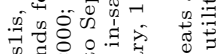

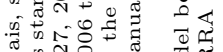

3.

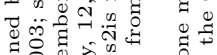

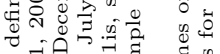

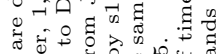

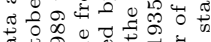

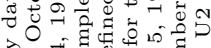

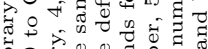

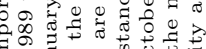

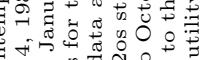

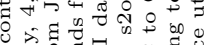

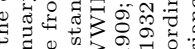

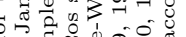

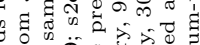

等

等

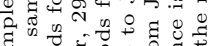

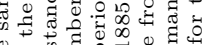

of

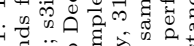

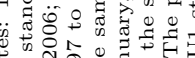

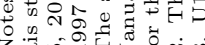




\section{References}

Diebold, F.X. and Mariano, R.S. (2002) 'Comparing Predictive Accuracy', Journal of Business and Economic Statistics, 20(1): 134-144.

Fama, E.F. and French, K.R. (1987) 'Commodity Futures Prices: Some Evidence on Forecast Power, Premiums and the Theory of Storage', The Journal of Business, 60(1): 55-73.

Fama, E.F. and French, K.R. (1988) 'Business Cycles and the Behavior of Metal Prices', Journal of Finance, 43(5): 1075-1093.

Giacomini, R. and White, H. (2006) 'Tests of Conditional Predictive Ability', Econometrica, 74(6): 1545-1578.

Irwin, S.H., Garcia, P., Good, D.L. and Kunda, E.L (2008) 'Price Convergence in Cash and Futures Grain and Soybean Markets', Choices, 23: 16-21.

Kroner, K.F. and Sultan, J. (1993) 'Time Varying Distribution and Dynamic Hedging with Foreign Currency Futures', Journal of Financial Quantitative Analysis, 28: 535-551.

Lee, T. (1994) 'Spread and Volatility in Spot and Forward Exchange Rates', Journal of International Money and Finance, 13: 375-383.

Lence, S.H., Hayenga, M.L. and Patterson, M.D. (1996) 'Storage Profitability and Hedge Ratio Estimation', The Journal of Futures Markets, 16: 655-676.

Lien, D. (1996) 'The Effect of the Cointegration Relationship on Futures Hedging: A Note', Journal of Futures Markets, 16: 773-780.

Lien, D. and Tse, Y.K. (1999) 'Fractional Cointegration and Futures Hedging', Journal of Futures Markets, 19: 457-474.

Lien, D., Tse, Y.K. and Tsui, A. (2002) 'Evaluating the Hedging Performance of the Constant-correlation GARCH Model', Applied Financial Economics, 12: 791-798.

Lien, D. and Yang, L. (2008) 'Asymmetric effect of basis on dynamic futures hedging: Empirical evidence from commodity markets', Journal of Banking and Finance, 32: 187-198.

Ng, V. and Pirrong, S.C. (1994) 'Fundamentals and Volatility: Storage, Spreads, and the Dynamics of Metals Prices', Journal of Business, 67: 203-230. 
Working, H. (1948) 'Theory of the Inverse Carrying Charge in Futures Markets', Journal of Farm Economics, 30: 1-28.

Working, H. (1949) 'The Theory of the Price of Storage', American Economics Review, 39: 1254-1262.

Zhong, M., Darrat, A.F. and Otero, R. (2004) 'Price Discovery and Volatility Spillovers in Index Futures Markets: Some Evidence from Mexico' Journal of Banking and Finance, 28: 3037-3054. 